Article

\title{
Rethinking Filter: An Interdisciplinary Inquiry into Typology and Concept of Filter, Towards an Active Filter Model
}

\author{
Khashayar Razghandi ${ }^{1,2, *}$ and Emad Yaghmaei ${ }^{3}$ (D) \\ 1 Biomaterials Department, Max Planck institute of Colloids and Interfaces, 14476 Potsdam, Germany \\ 2 Matters of Activity, Image Space Material, Cluster of Excellence Humboldt-Universität zu Berlin, \\ 10099 Berlin, Germany \\ 3 Department of Values, Technology and Innovation, Faculty of Technology, Policy and Management, TU \\ Delft, 2600 AA Delft, The Netherlands; E.Yaghmaei@tudelft.nl \\ * Correspondence: khashayar.razghandi@mpikg.mpg.de
}

Received: 30 June 2020; Accepted: 30 August 2020; Published: 4 September 2020

\begin{abstract}
This work aims to re-investigate different aspects of a variety of filters and filtration processes within diverse realms of knowledge from an interdisciplinary point of view, and develops a comprehensive Active Model of Filter that accommodates the phenomena in its entire diversity and complexity. The Active Filter Model proposes to take Filter-from various fields and scales operating at material and symbolic level—not as mere objects, but as difference-producing phenomena that need to be addressed as complex active systems within event-based boundaries. The model underlines a systemic, operative, performative, and negentropic nature to the phenomena that invites one to; recognize various elements and intra-actions within a filter system; follow chains of operations and processes that render the activity; take the performative and ecology building aspect of the filter activity into consideration; and acknowledge the negentropic, order-producing nature of filtering phenomena. The Active Filter Model is meant to serve as a foundation for further analysis and synthesis in various fields dealing with Filter, and the research approach is put forward as a paradigm for how seemingly disciplinary concepts such as Filter can be rethought through interdisciplinary methods, and mutually complement research questions within active matter, biology, information philosophy, data science and sustainability discourses.
\end{abstract}

Keywords: filter; active matter; material; information; systemic; ecology; membrane; data science; sensor; sustainability

\section{Introduction}

Filters and filtering operations are at the core of many of the products, services, and information that is being produced and consumed. From chemical industry, waste management and recycling to search engines, AI, and insurance policies, filtering is of concern in various disciplines and fields [1-5].

The ubiquitous presence of the term within these broad realms is highlighted in the fact that it is usually described not according to a general or universal definition, but within a set of categories. The Merriam-Webster dictionary lists different definitions of filter, as a noun, in four categories which relate to the diverse use of the term in different fields: I) As in a physical separating article or apparatus that "separates out matter" in liquid or gas medium; II) as devices to suppress waves or frequency of some type, for instance, in signal processing [6,7] and electronics [8,9], or optical [10] and acoustic filters [11,12]; III) as in the more abstract sense of an analogy, something that has the effect of a filter, for instance a biased mind; and IV) in the software and internet realm ("Filter." Merriam-Webster.com Dictionary, Merriam-Webster, https://www.merriam-webster.com/dictionary/ 
filter. Accessed 4 Jun. 2020). Even more remarkable is how filter as a verb is defined there through referral to filter as a noun, an object: "To subject to the action of a filter", "to remove by means of filter", "to pass or remove through or as if through a filter". Filter, as an object, is the locus of the discourse, and "filtering" comes secondary through association to "filter".

The following will briefly review a few relevant works on this theme, to gain an understanding of the terms that are already more broadly discussed.

In recent years, some scholars tried to give a more active understanding of filter by analysing historical as well as contemporary works on "membranes" [13-16]. In their anthology Membranes, Surfaces, Boundaries from 2010, Mathias Grote and Max Stadler called membranes of different sorts "un-dead surfaces" or "surfaces in action" [14]. In the same book, the cultural historian Thomas Brandstetter discusses the production of artificial cells in the laboratories of the 1840s, and highlights the fact that at that period, physiologists discovered that osmosis, as something that characterized the functioning of living cells, could be performed outside of the body. Brandstetter showed that the activity of these membranes was situated somewhere between strictly mechanically understood processes and strictly vitalistically understood forces within the living body. These cells in petri dishes exhibited an agency of life and challenged the existing categorization as purely biological or mechanical [16,17].

This more active view of filter has been pointed out in parallel in the current discourse of active matter. Active matter is a term under discussion in recent physics, biology, chemistry, and material sciences that address and analyse the nature of activity in matter. The term covers a range of studies such as; emergent global pattern through collective behaviour of particles; natural or synthetic autonomous actuation and responsive systems, and so on [18-20]. The term is usually associated with the swarm behaviour of flocks of birds or shoals of fish, which can be understood as collective movement of discrete particles in a medium, regulated through local interaction rules, resulting in emerging global behaviour of the collective as a whole $[13,20]$. In his text on Active Matter from 2010; the physicist Gautam Menon, one of the central figures on the topic, names under the headline "Active Matter Systems: Some Examples", not just the dynamic swarm behaviour in bird flocks, fish schools, and bacterial suspensions, but also refers to "active membranes" [13]. Menon notes: "It is interesting that several developments in the theoretical description of generic active matter reflect ideas first introduced in the context of active membranes". Later on, in his book Membranes to Molecular Machines: Active Matter and the Remaking of Life, Grote takes a historical view of the understanding and modelling of cell membranes as active surfaces in 20th century and, connecting it to contemporary research in biology, biomolecular, and nanoscience, puts forward a view of membranes from an active matter perspective [15].

From these perspectives, function of such semipermeable membranes was understood as a filtering activity, facilitating and regulating exchange. In regard to the regulating and order-producing agency of such a filtering membrane, Maxwell's Demon can serve as a model for the activity of a semipermeable membrane. In his book on thermodynamics, The Theory of Heat, James Clerk Maxwell came up with a thought experiment in which he introduced a creature that in a vessel filled with air would be able to observe the moving molecules and open or close a door in respect to their velocity. Over time, the fast molecules would gather on the one side and the slower on the other, thereby leading to an apparent paradox with the entropy principle of the second law of thermodynamics. The second law states that in an isolated system the total entropy cannot decrease, and the system would evolve toward a maximum entropy equilibrium state [21]. Semipermeability can be understood as the demon acting out the capacity for a thermodynamic self-organization, as the effects of filter processes enabled on a material level. The membranes filter activity in this regard is composed of two qualitatively different sides and one membrane in between, that enables the exchange of certain elements between the two sides (e.g., molecules of a particular size or shape), or selects elements of a certain quality out of a medium, etc. Hence, in this paradigm of regulative exchange, the filtering function can be described as an act of controlled separation that is enabled by the material structure of the filter. 
Moreover, the membrane is sometimes used as an epistemological model in order to describe regulative exchange beyond the domains of biology or physics. The literary scholar Laura Otis in her book Membranes: Metaphors of Invasion in Nineteenth-Century Literature, Science, and Politics [22], describes how the prominent metaphor of the biological cell-wall was used in 19th century science and fiction. Otis writes: "The concept of identity that emerges from cell theory and its fictions-I shall call it the membrane model—is based on exclusion" [22]. With this way of deploying the membrane, aspects of separation, invasion, and regulation are emphasized in regard to historical notions of identity in the 19th century.

To summarise, the current understanding of the filter phenomena place the focus on filter as an object. Even within the contemporary works of Menon, Grote, and others on a more active understanding of the semipermeable membrane activity, the focus is still on the filter as an active element, object, material, and less on the systemic and procedural aspect of the phenomena. This object-view of the filter reveals its shortcomings from the first glance into those diverse instances where different fields refer to the phenomena in their hand as filter and filtration. Moreover, the current discourse revolves around the idea of regulative exchange as in the "membrane model". This membrane understanding of regulative exchange, not only as Otis writes moved into and influenced various fields of economy and politics, but also has lived on to define the main paradigm of the more recent "filters" within the world of computation, data, internet, and so on.

Although the idea of using such an epistemological model of filter and of transferring it to other realms of enquiry is in principle appealing, there is more to filtering that goes beyond the object or membrane model. The existing models generally tend to focus on just one dimension of filter and fail to engender a holistic perspective that addresses the typology and ecology of the phenomena.

This paper identifies a need for a framework for filtration beyond the existing ones. The filter topic is interdisciplinary by nature, and can be approached from various perspectives of physics, biology, materials sciences, as well as cultural history, media theory, information philosophy, and so on, and any reductionist explanations might miss the larger systems and processes at work.

Our objective is to, on one hand, address the inherently interdisciplinary nature of the topic of filter, and on the other hand, to develop a novel trans-disciplinary model of filter that is based on an active and comprehensive understanding of the phenomena to systematically rethink the ontologies, ecologies, activities, and value systems associated with filter.

To fulfil this, our approach is to, while having a historical dimension in perspective, explore a variety of examples from contemporary developments within a wide range of research projects in the natural and social sciences that investigate filter materials, filter systems, and processes (Figure 1). A comprehensive Active Model of Filter is then built on the thorough study of the examples, to elucidate various aspects of the phenomena in the fields dealing with the term, and encourage further analysis and synthesis. Such an Active Filter Model would, on one hand, serve to address and assist a broad community of academics and industries in better understanding filter models within their activities, and developing more responsible practices thereupon, and on the other hand, can open new perspectives on locating and addressing the filter theme within a diverse realm of knowledge such as Active Matter, thermodynamics, abiogenesis, biology, ecology, information philosophy, media theory amongst others.

In the next chapters, we put a handful of filters from diverse realms of biology, material science, information and communication technology and so on under the spotlight and briefly go over the filter phenomena and their main filter "features" in each of the examples. Subsequently, we'll use these as a context upon which we base our analysis work, and introduce a few aspects as the most relevant characteristics of the filtering phenomena. 


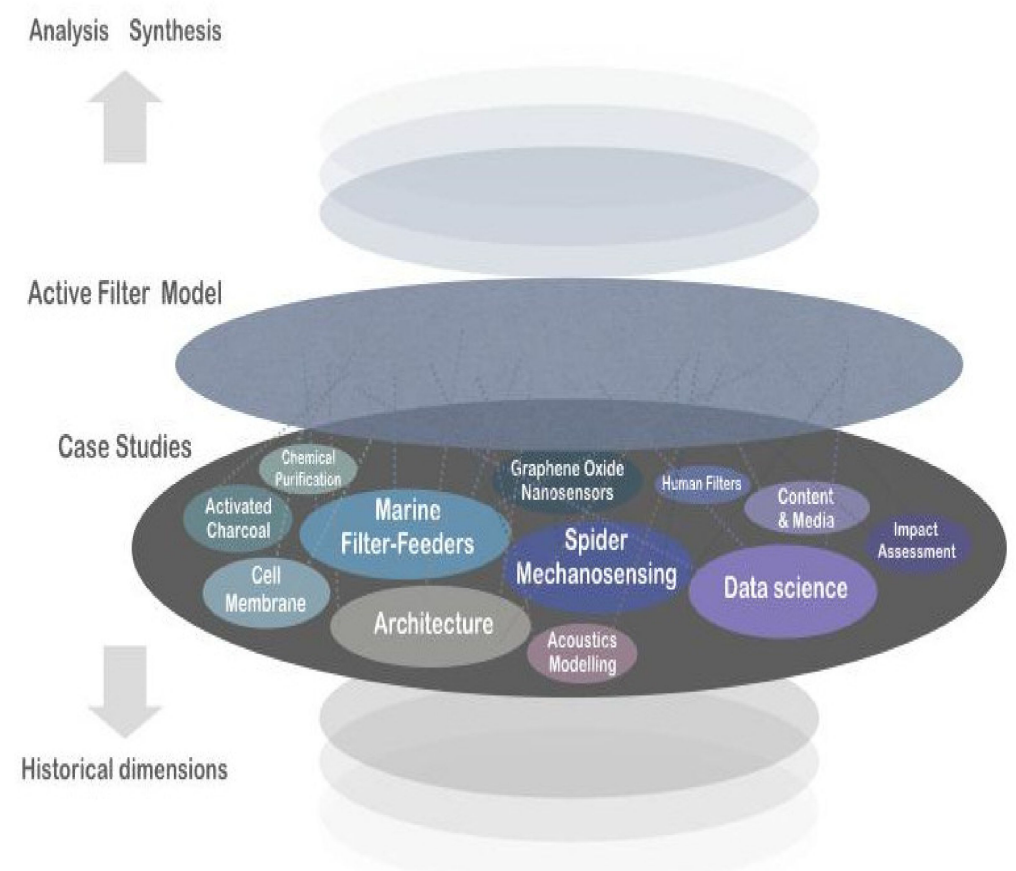

Figure 1. Structure of the research. Schematic presentation of the rationale and structure of the research; with a historical dimension in perspective, explore a collection of various filter phenomena from various fields and scales operating at material and symbolic level, to develop a systemic and Active Model of Filter phenomena, that could serve as a ground for a more comprehensive analysis and synthesis practices.

\section{Methodology}

The idea of this interdisciplinary collaboration originated from a series of discussion rounds on seemingly unrelated filters in two projects situated within natural science and cultural history and theory; the structure-function relationship of a marine filter feeder and the operative aspect of architecture. This early phase resulted in consolidation of the first series of research questions: What is filter? If there are commonalities between filters and filter operations within the diverse fields and realm of knowledge that use the term? What kind of material or symbolic structures and organizations occur? How is the procedural, the potential for filtering and separating, related to the structure? How can the activity of filter systems be described in material and symbolic terms? Could filter serve as an epistemic model for material activity beyond the dichotomies of symbolic and material, information and organization, mechanistic or vitalistic explanations?

The first step to address these initial questions was organisation of an interdisciplinary workshop on the typology and concept of filter within diverse fields. The studied examples within the workshop ranged from cell membrane, mechanosensing in spider, acoustics modellings, and filter in data science, among others. The workshop was followed by a thorough analysis of each of the contributions from a joint natural science and cultural history perspective.

Further analysis of the collection of these initial contributions led to further research questions and investigations, either within the same field, as for the case of filter in architecture, while others led to a labyrinth of research questions that ended up in a seemingly unrelated field, as in the case of moving from data science and media to internet content moderation, human filters, and pathology of informational filters. A few more examples were later on identified and added to the collection of case studies. For instance, in the case of Graphene Oxide Nanosensors, an interview and thorough discussion with the expert in the field complemented the preliminary understanding of the phenomena, while the filtering in impact assessment was introduced as to the collection in the late stages (More details on the contributions in the acknowledgment section). 
The diagram in Figure 1 depicts the rationale of the research as well as the collection of various case studies from diverse fields. The list is non-exhaustive, but our main selection criteria, beside the intriguing nature and relevance of some of the cases to the rationale of the work, was to have broad exploration through various fields and realms of knowledge, and bring examples that cover different senses of complexities and depth; occurring at various scales and forms; and dealing with physical as well as symbolic attributes of the phenomena. Through all of this, we kept our initial questions as a spotlight to speculate on the nature of Filter.

\section{Case Studies}

In the next chapter, we put a collection of examples that deal with filter and filtering within different fields under the spotlight and go through various aspects of their filtration and activities in various realms to establish a basic common understanding of the filter phenomena in each case.

\subsection{Chemical Purification; Activated Charcoal}

In chemistry, (chemical industries, metallurgy, biochemistry etc.), there are purifying processes and methods, where the contaminants or unwanted substances are "filtered out" through a variety of separation methods. The filtration can be achieved through physically separating a (usually) solid element within a fluid (liquid or gas) by passing the mix through a porous or semipermeable membrane, that acting like a sieve, allows the flow of the fluid while restricting the passage of the other elements with certain sizes or features. However, the purification is not restricted to this "membrane filtration", and can include a variety of processes such as centrifugation [23], liquid-liquid or solvent extraction [24], affinity purification [25], electrolysis [26], and phase separation [27], amongst many.

In phase separation, for instance, filtering happens with two parts involved. A simple case of phase separation is the familiar oil-vinegar mix (Figure 2, right). Molecules with similar affinities attract and cumulate while repelling the one with different chemical affinity. Lipids, here the oil, are hydrophobic and don't mix with the water within the vinegar, and as a result oil and vinegar form two phases. Here and in other phase-separation phenomena, the separation occurs as self-organisation due to different physicochemical properties, which can be utilised as a mechanism to cumulate and select out some desired elements, or to purify a medium by filtering out undesired elements [27].

Purification through adsorption is another filteration mechanism that goes beyond membrane activity. Adsorption is defined as a surface process where atoms and molecules of a fluid (gas or liquid) adhere into the surface of a solid [28,29]. Figure 2 shows an SEM-image of activated charcoal. The main characteristic of such material is its high porosity, which translates into a large inner surface area compared to a relatively small volume. The high available surface area results in high adsorption of large amounts of particles flowing within a fluid medium on the inner surface of the activated charcoal $[28,29]$. Such porous materials with high adsorption properties are widely used in gas and water filtration technology $[30,31]$. As soon as the charcoal comes in contact with a medium like water or streaming air, its filtering is initiated. The filtered particles accumulate in the charcoal over time, thereby decreasing its filtering function. To reuse it, it needs to be cleaned, which is done by heating the coal and thereby reactivating it.

This technology is not new. Already in the early 19th century, people used charcoal for cleaning their water. The dirty water would seep over time through the charcoal part in the middle of a vessel, and eventually the filtered drinking water could be collected in the bottom. Already in the early 19th century, there were conversations around the nature of this filter process. Chemists as well as physicists had trouble understanding how it actually worked. There were different interpretations, ranging from the idea that the coal is swallowing the dirt, to the idea that it is "compressing" the particles, to the assumption that there is a spontaneous oxidation happening within the coal. What these concepts have in common is an understanding that the coal is exhibiting some sort of activity-even called disinfecting agency—emphasising on the filtering agency of the activated charcoal. 

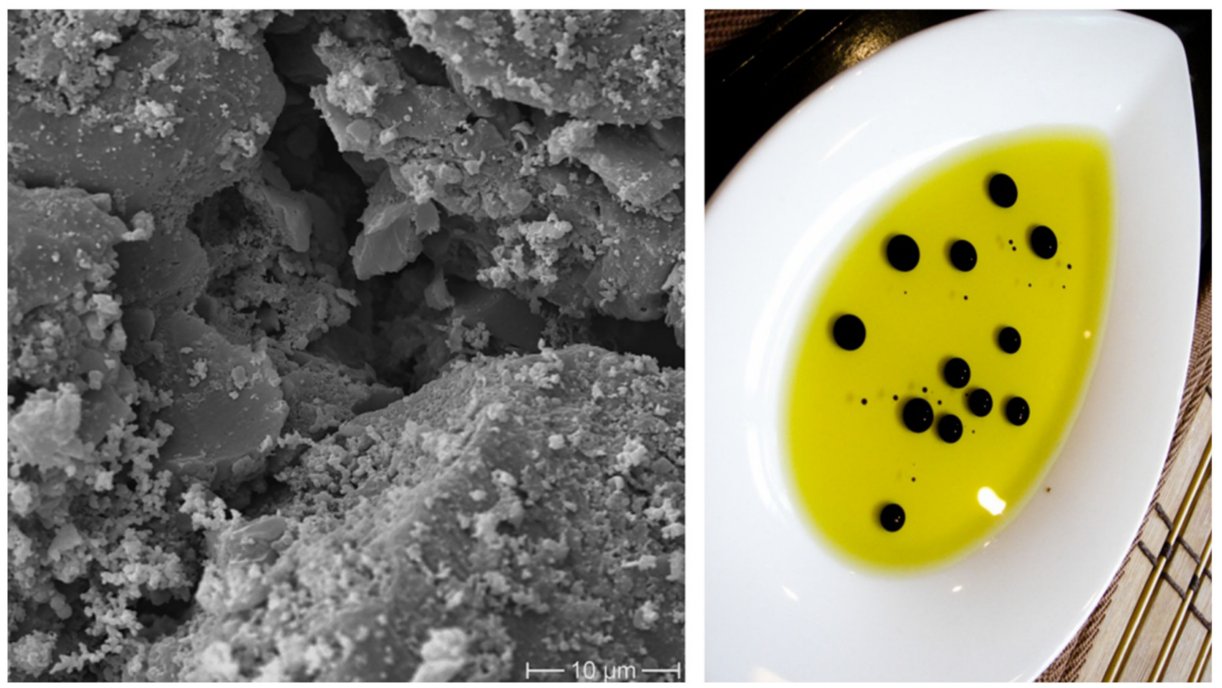

Figure 2. Chemical Purification; examples of adsorption and phase separation: (Left) Active charcoal. Scanning electron microscopy micrograph of activated charcoal showing the large available surface area resulting in high adsorbability. (Right) Phase separation of oil and vinegar. Hydrophobic oil and hydrophilic vinegar separate into two different phases, which can be used to filter one out of the other (images adapted from Wikipedia common. (Left) Wikimedia Commons contributors, "File:Activated Charcoal.jpg," Wikimedia Commons, the free media repository, https://commons. wikimedia.org/w/index.php?title=File:Activated_Charcoal.jpg\&oldid=417429816; (Right) Wikimedia Commons contributors, “File:Olive oil with Balsamic Vinegar.jpg," Wikimedia Commons, the free media repository, https://commons.wikimedia.org/w/index.php?title=File:Olive_oil_with_Balsamic_ Vinegar.jpg\&oldid=331512136 (accessed 17 June 2020).

\subsection{Cell Membranes}

One of the universal features of cellular life is the encapsulation of the machinery of life within a membrane (also known as plasma membrane) that separates it as an autopoietic entity. The cell membrane, in this sense, is not only an enclosure, a boundary separating the inside (the cytoplasm and content of the cell), from outside (the surrounding environment), and giving the cell its structure, but is also a selectively permeable boundary that regulates the amount of a substance in the cytoplasm or facilitates the exchanges that are necessary for survival and maintaining the functions of such a living entity [32] (Figure 3).

The cell membrane is a lamellar structure made up of lipids and proteins; two monolayers with hydrophobic hydrophilic (water-soluble) and (water-insoluble) sites are laid on top of each other through a self-assembly process, in a way that the hydrophobic sites (fatty lipids) face toward and are gathered in the middle of the wall, while the inner and the outer part are the hydrophilic sites. A large amount of various proteins are embedded within this few-nanometer-thick hydrophilic-hydrophobic-hydrophilic structure. Even within the cell there are membrane-bound organelles with similar lipid membrane structures [32-35].

Self-organization and Liquid-liquid phase separations leads to generation of such thin two-dimensional liquid interfaces that can act as regulatory boundaries. The filtration and exchange of substances into and out of these interfaces are regulated through a multitude of criteria. Membrane Pores, predetermine some size selection or some gradient flow. Time is another important element in any such processes, as given enough time, everything can diffuse and pass eventually. The transport can occur passively through a diffusion and flow of substances, molecules, and proteins across the membrane, but transporters, or membrane transport proteins, play a crucial role on the active transport and exchange across the membrane, which spent energy to achieve a selective process and movement of substances across the interface [32-35]. 
The cell membrane, as such, can be seen as an active filter that regulates certain aspects and functions of the two sides of the interface. Filter here is the structure as a whole, the channels and highly selective transporters allowing passage of molecules, ions, and proteins through the interface. There are also some recycling mechanisms that can be involved to selectively manipulate or degrade part of the membrane to render the cell membrane a more active self-regulating filter system.

Such self-organized enclosures and interfaces can be synthesized and further modified into functioning as an exchange regulating fronts, or filters. In contemporary works in synthesis of biomembrane-like vesicles within biophysics analysis, synthetic biology, or drug delivery, the "cell membrane" can have a different structure, shape, and size depending on the membrane properties, to facilitate certain regulatory function of the interface as physical/physicochemical filters [36].
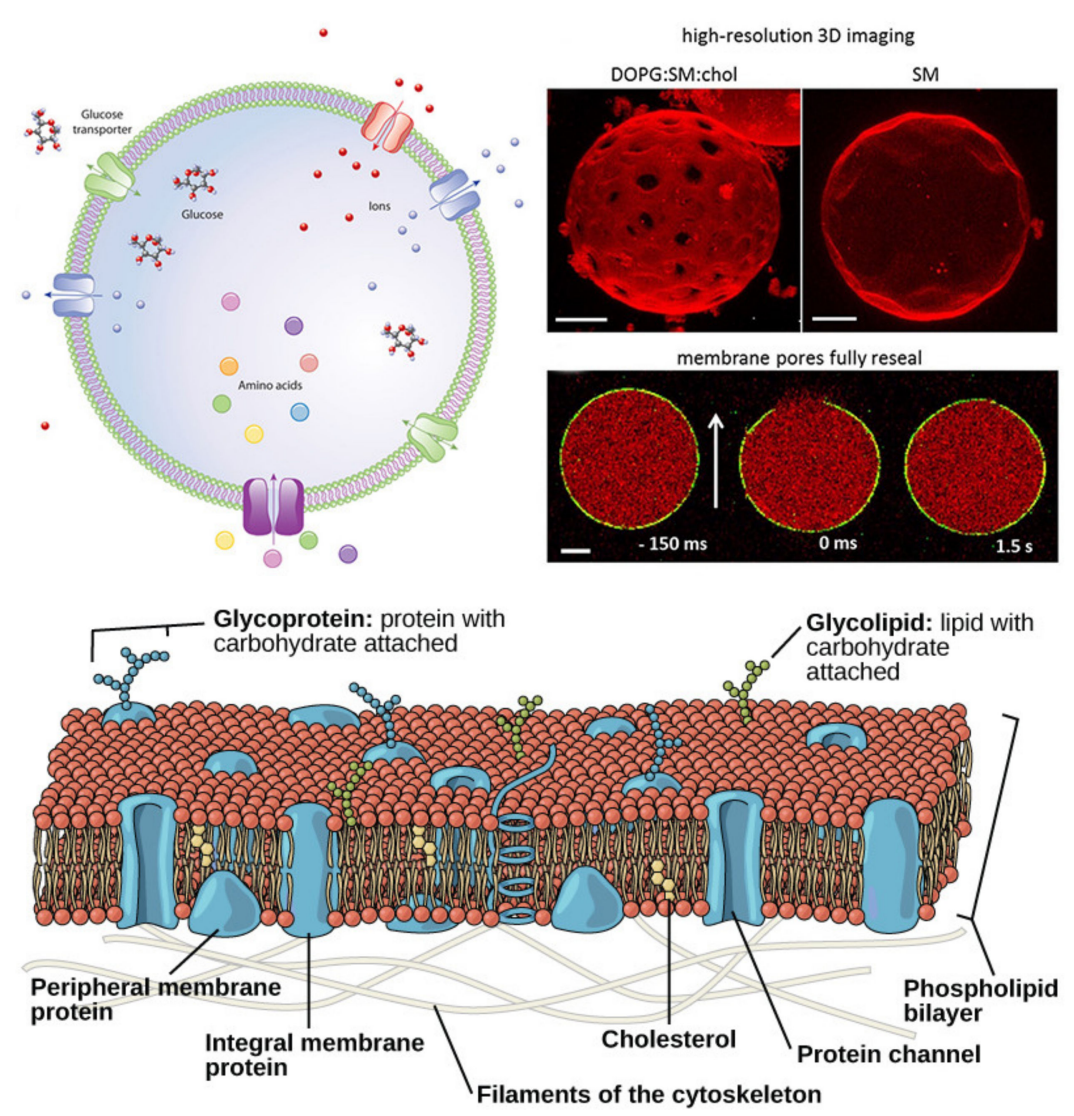

Figure 3. Cell membrane. Top-left: The plasma membrane selective transport; transporter proteins use energy to selectively transport substances in and out of the cell, regulating the concentration of different molecules and ions (adapted from [32] (C) Nature Education). Top-right: High-resolution 3D images of two exemplary Giant Unilamellar Vesicles (GUV); synthesized simple cell-sized model membrane systems, that are typical for studying and modelling of various features and characteristics of the more complex biological membranes. Confocal snapshot of the GUV shows an example of the before and after membrane poration induced by an applied DC pulse (image adapted from [37] under a Creative Commons Attribution 4.0 International License). Bottom: The fluid mosaic model of the cell membrane: The fluid plasma membrane consisting of the bilayer phospholipids, cholesterol, and proteins (image adapted from [38] licensed by CC BY-NC-SA 3.0 US). 


\subsection{Filter-Feeders; Larvacean Tunicates}

The Appendicularian tunicates are solitary swimming marine animals that produce a cellulosic structure which serves as a food-filtration system. The animal secretes an elaborate folded tissue, which in the rudimentary state is wrapped around the trunk of the animal, ready to be unfolded into a transparent multi-chambered structure when pressurized through the complex movement of the animal [39-41].

The inflated structure is an elaborate configuration of different membranes, channels, chambers, and accumulation nets. The undulatory beating of the animal's tail produces a pressure potential between the inside and outside of the structure. The surrounding water is then sucked into the structure through the two side inlet filters, passes through multi-chambered structure, and is released back to the surroundings through an outlet. As the sea water is pumped through this infrastructure, at the first stage the bigger unwanted particles are stopped at the inlet filter meshes, while the water and smaller food particles continue through the tail chamber toward two side passages and into the food-concentration-filter on each side. The food particles (algae, etc.) get trapped in between a complex of meshed tissues, and the pulsating opening/closing of these meshes due to water flow and pressure changes results in accumulation of the food particles, which are then directed toward a convergence zone, into a tube, and eventually to animal's mouth (Figure 4). The filtering system, as a whole, comprises cellulosic membranes and meshes, sophisticated interconnected chambers, pulsating walls, the undulating tail of the animal, pressure potentials, water flows, and the animal's digestive system, amongst others.

The structure is ephemeral, as it gradually gets clogged over time, and every couple of hours, the animal escapes the structure and replaces it by unfolding and inflating a newly secreted rudimentary house wrapped around its trunk. The discarded house collapses. Without the inner-pressure induced by the animal inside of it pumping water in and out, the mucus gelatinous structure loses its integrity, moves about with water currents, and eventually falls to the ocean depth and contributes to a significant portion of particulate organic carbon and oceanic carbon cycle [42,43]. The whole system gains its integrity from its mobility and function, and the filter is only there when the filtration is happening.

There have been attempts within biology to describe animal-built structures with less dividing concepts. In his monograph Animal Architecture and Building Behavior from 1984, the biologist Mike Hansell described animal-built structures as "frozen behaviour" [44], which still implied a static concept of animal architectures. Evolutionary biologist Richard Dawkins argues in his book "The extended phenotype", that although genes only directly control the synthesis of proteins, they have an effect on the environment and the phenotype should be "extended to include all effects that a gene has on its environment, inside or outside the body of the individual organism" [45]. In his book The extended organism. The physiology of animal-built structures, the biologist J. Scott Turner promotes animal-built structures as "organs of physiology". He extends the physiology of animal organisms to structures such as termite's mounds, coral reefs, or plant galls. Turner examines the effect of the environment upon the organism and the effect of the organism upon the environment [46]. These concepts, as fruitfull as they are, still think of the animal as being in charge of its structure. Focusing on the filtering function of tunicates, a clear boundary between animal and structure blurs; both are crucial parts of the filtering system. The structure is not a mere "add on" to the animal, as it is neither a part of the animal in the narrow sense of an organ, nor can it be considered as some kind of shelter or external tool completely separated from the animal. Under this filter perspective, the focus changes from what the animal and the structure are, to what they do; filtering. 

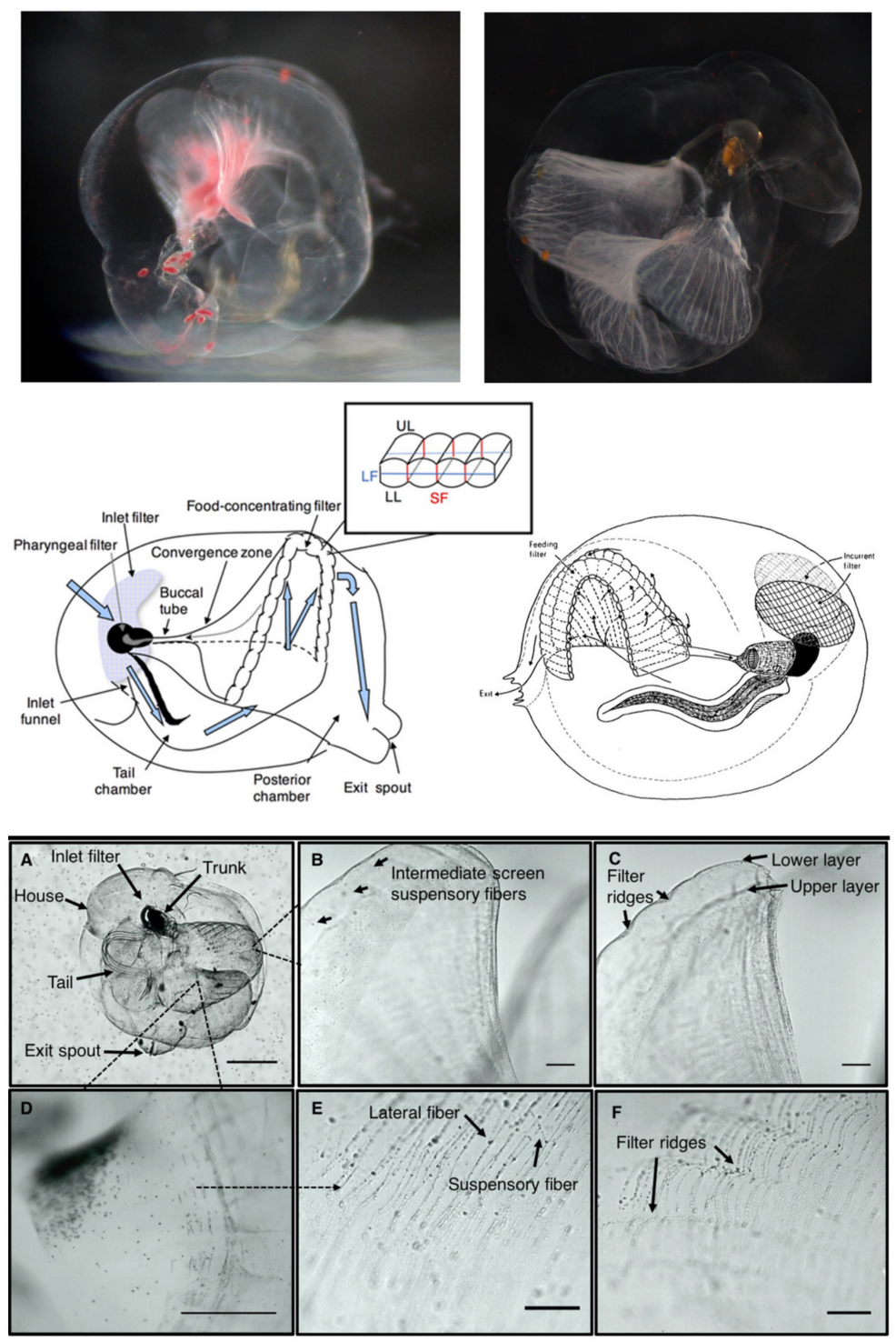

Figure 4. Filter-house of the larvacean tunicates. The images on top show the Appendicularian Oikopleura dioica inside its filter-house. Food particles (white or red) are sucked in from the surrounding water into the transparent filter-house and make it visible (images by the Author Khashayar Razghandi). The schematics in the middle illustrate a simplified model of the water flow and filtration path (middle-left adapted with permission from [41], the middle-right image adapted with permission from [39]). The subsequent brightfield images-Originally assigned as $\mathbf{A}$ to $\mathbf{F}$ - depict the intricate structure of the main food concentration filter (FCF), showing the effect of the tail beat and arrest cycle on the structure of the FCF wings (B,E and C,F respectively), which trap and accumulate the food particles and lead them toward the buccal tube (dark spot in $\mathbf{D}$ ). (image adapted with permission from [41]). Scale bars: (A,D): $0.5 \mathrm{~mm} ;(\mathbf{B}, \mathbf{E}, \mathbf{F}): 0.1 \mathrm{~mm}$. The diameter of the filter-house ranges from 2 to $5 \mathrm{~mm}$ depending on the animal's age.

\subsection{Graphene Oxide Nanosheet Sensors and Inhibitors}

Moving from the physical filtering of particles to the realm of sensors and responses, this chapter explores the function of modified graphene oxide nanosheets in chemical sensors and pathogen inhibition, where the activity of the system lies at the molecular and nanoscale [19].

Graphene sheets are two-dimensional materials comprised of hexagonal arrangements of carbon atoms, and represent a class of materials that are only one atom thick [47] (Figure 5 top). Graphene oxides (GO) are highly oxidized graphene sheets with oxygen containing groups, and can exhibit 
distinct electronic and conformational properties that can give rise to a range of novel performances and functionalities [48].

The number of oxygen containing groups on the graphene oxides plane can be thermally reduced (rGO or TRGO) to tune the charge mobility on the plane ranging between the unrestricted mobility in graphene sheets to relatively insulating properties of graphene oxide sheets [48]. Moreover, adsorption of different analytes onto the surface of the reduced graphene oxide sheets can also change its conductivity. This tunable conductivity can be exploited to create highly sensitive macromolecular chemical sensors with applications, for instance, in chemical safety and security $[49,50]$.

Another example of how the activity of such 2D systems can be translate into application is the pathogen inhibiting behaviour of the functionalized thermally reduced graphene oxide. Introducing dendritic polyglycerol polymer chain branches (dPG) to the plane enables the chemical modification of the branches and introduction of a variety of functionalities into the macromolecular system. For instance, the end branches can be modified and functionalized to give the possibility of interaction with the outer membrane of pathogens [51,52]. The high number of these functional sites on the 2D sheet can adhere to the pathogen at multiple sites, and when one site interacts and adheres, the attachment force locally bends the 2D sheet and brings the next functional site in proximity of the organism and the next site attaches, and in a cascade of chain events, more and more sites click and attach one after another, and like a zipper, the nanosheet wraps around and entraps the pathogen (Figure 5 bottom) [53].
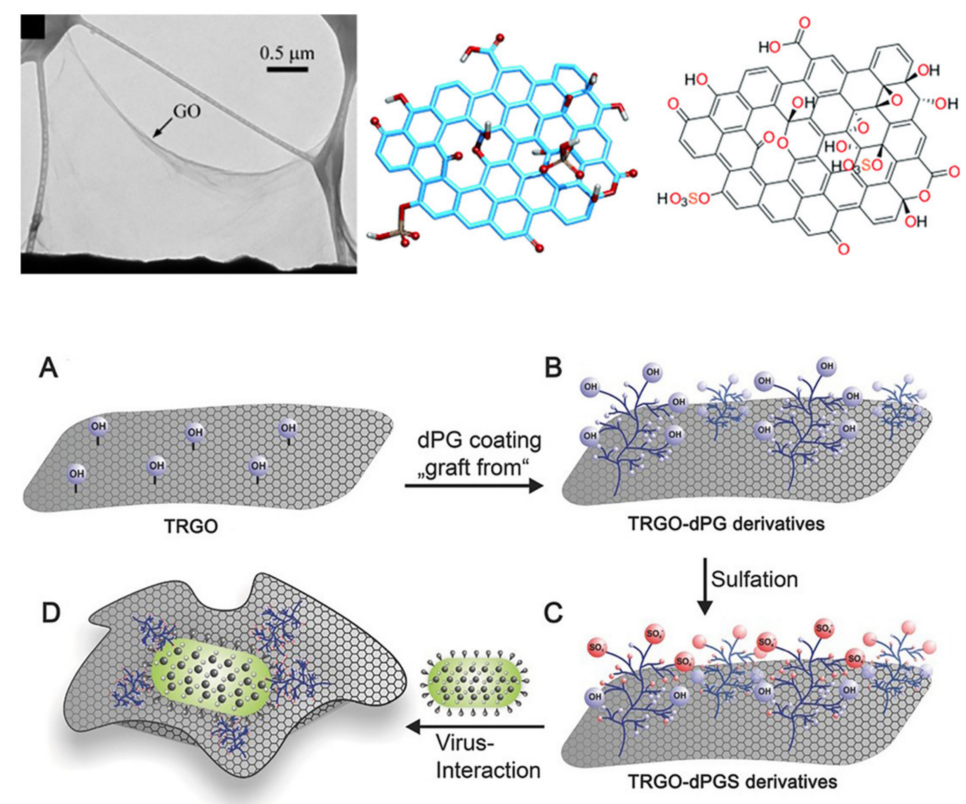

Figure 5. Graphene oxide nanosheets as pathogen inhibitors. Top row: Transmission electron micrograph of a single graphene oxide (GO) 2D sheet on the left; and structural model and formula of an exemplary GO on the right (The top-left image adapted with permission from [50], and the top-right image partially adapted with permission from [48]). Bottom: The schematic of a thermally reduced graphene oxide sheet (TRGO) is shown in the image sequence A. The TRGO can be coated with the dendritic polyglycerol polymer chain branches (dPG) shown in B. The added brancheds can be further sulphated and functionalized, as shown in image sequence $C$, with red sulphated functional groups sitting on top of the dPG branches. The electrostatic interactions of these functional groups with the outer membrane of a virus can lead to conformational change of the nanosheet and entrapment of the pathogen as depicted in $\mathrm{D}$ (the bottom image sequence A-D is partially adapted with permission from [54]).

The basis for this is that the energy exchange with the environment can lead to geometrical conformational or configurational changes in the angstrom and nanoscale, and one can make use 
of this to tailor at a higher macro scale. In this case, the selection and separation (filtering out) of a virus is a result of the interaction of the nanosheets' functional groups and the pathogen membrane at nanoscale. Moreover, the 2D sheets can be functionalized and specialized to react with and remove only specific entities within a system. It is this selective interaction and operation of certain functional groups on the nanosheet with an outer membrane of a distinct virus or class of viruses that lead to inhibition and filtration of the pathogen out of a system. The interaction at nanoscale brings about the selection and separation at macro scale.

\subsection{Mechanosensing in Spiders}

Most spiders have a highly sophisticated sensory system in their bodies that enables them to perceive their environment through the vibrations in their immediate surroundings. Cupiennius Salei are spiders that live mainly on banana leaves in central America, and their bodies feature an elaborate system of vibration sensors that helps them to detect and process vibrations at a material level $[55,56]$. One part of this sensory system is the chitin-based lyriform organ that is located between the tarsus and metatarsus, at the legs joints. The vibrations in the surroundings resonates in the substrate leaf where the spider is sitting. Upon small movements of the leaf, the tarsus (the part of the leg lying on the leaf) gets deflected upward and touches what is known as the cuticular pad on the joint (Figure 6 top). This movement is further translated into an opening and closing of slits with different lengths located there (Figure 6 bottom-left). Each slit is covered with a protein coat called epicuticle membrane, which is connected to a nerve cell, so that slight vibrations of the slits induce an action potential in the underlying neuron [55-57].

The response from various slits within this sophisticated mechanosensing system translates the surrounding vibrations into distinct "signals" with specific frequencies and repetition patterns, each mapping to different known stimuli (Figure 6 bottom-right). As a result, the appropriate response of the spider follows accordingly; is it an approaching prey to hunt?; a fellow spider on a nearby leaf?; an immediate danger to avoid?; or a background noise, like wind, to ignore [55]?

The main part of signal filtration and processing happens at the material level; for example, the lyriform organ filters out low-frequency background noise with no informational value. Various experiments have shown how the geometrical arrangement, material structure, and mechanical properties, along with environmental factors such as temperature or the stance of the spider, each can play a role in the filtration process. Long slits are more flexible compared to shorter slits that need more force to be compressed. The relative location of the slits on the organ play a role in the final interpretation of the signal. The stance of the spider on the leaf plays a role in the transfer of the vibration from the leaves to the joints. The mechanical properties of the cuticular pad are temperature dependent and is different during the day and night; the material has lower modulus of elasticity when it's hot, thus it is less sensitive, while at low temperature of the night, the modulus of elasticity rises, and the tissue become stiffer and more responsive, which would make sense for a nocturnal species [55-60].

The system as a whole enables the highly specific filtration of the surrounding stimuli at the material level. On the first filtration level, among all different existing vibrations in the surroundings, only a certain range, relevant for the survival of the spider, is detectable by the system. Then, within the detectable vibrational range, the system distinguishes the useful from "useless" information, what can be described as "filtering out of background noise". Finally, vibrational input is split up into different categories, and it is classified into what spider perceives as "prey", "other spider", or "wind", for instance. The filtration of the vibration and processing of stimuli here is achieved not just by the nervous system alone, but is substantially pre-processed and filtered through animal body and material structure and properties. This process at the material level and in the periphery and mainly outside the central nervous system reduces the brain processing and, eventually, the spider's sensing and acting time. 

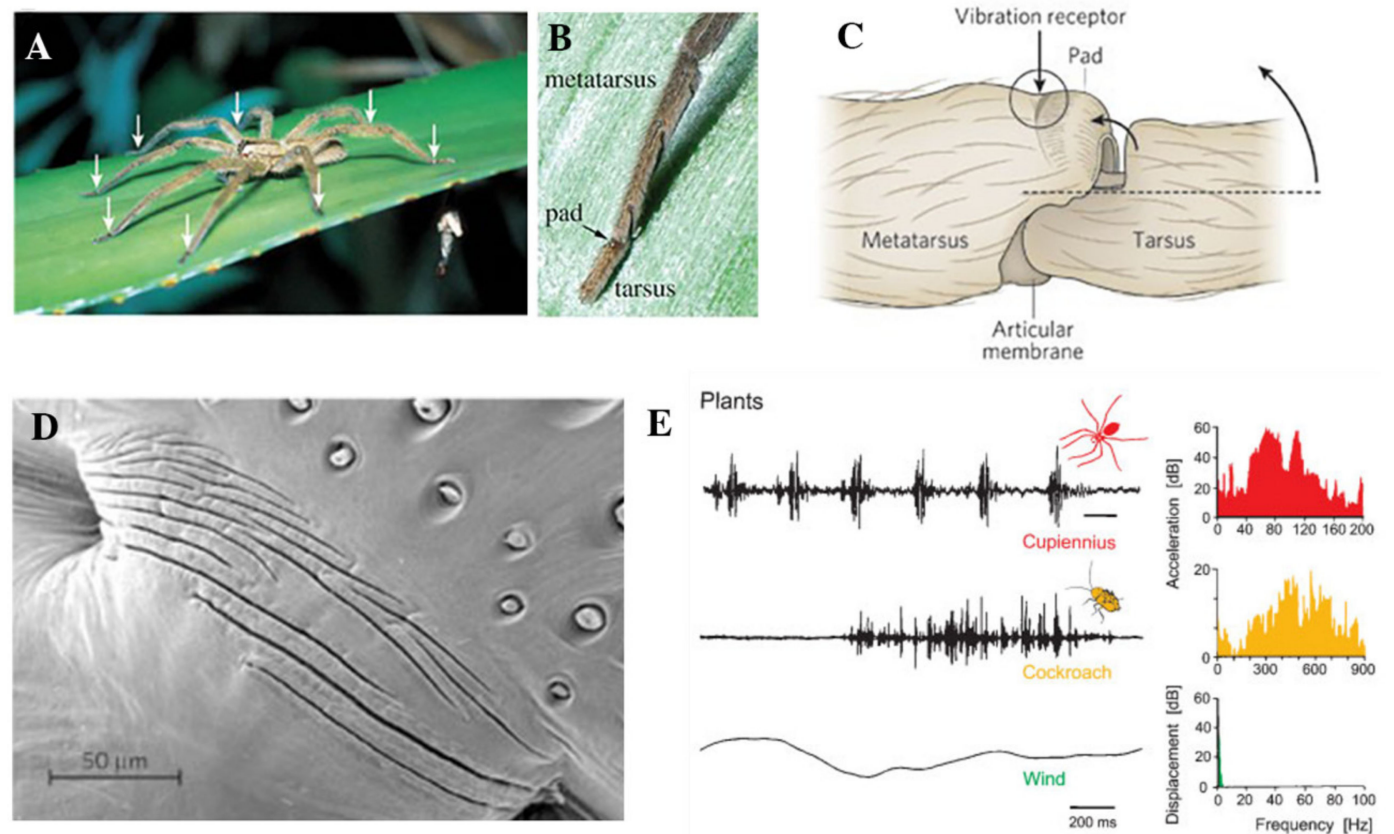

Figure 6. Mechanosensing in spiders. (A) and (B). show the spider Cupiennius salei sitting on a leaf with the location of the vibration sensors shown with arrows ((A) partially adapted with permission from [56]; (B) partially adapted with permission from [58] under the terms of the Creative Commons Attribution License 4.0 International (CC BY 4.0)). (C). depicts the relation of the vibrational sensor on the metatarsus, the cuticular pad, and the articular membrane, and how the system is stimulated when the upward movement of the tarsus compresses the pad (partially adapted with permission from [56]). (D). shows a scanning electron micrograph of the metatarsal organ and the vibration detector slits (The SEM micrograph (D) adapted with permission from [56]). The vibrational environment of the spider in its natural habitat is shown in (E), with the frequency spectra on the right side and the oscillograms related to specific vibration on the pseudo-stem of a banana plant on the left (image adapted with permission from [59]).

\subsection{Modelling Acoustic Transmission Systems}

Acoustic bend, or what is called sound, is patterns of pressure waves happening in material form, and there is no sound without matter. From the initiation of the material wave from a source to reception of it in a receiver, there is a chain of transection, where the mechanical waves have to pass material things, walls, windows, obstacle, barriers, air molecules, and so on, which influence the final received acoustic. Hence, all physical acoustics are subcategories of filters.

The material process in acoustic transmission which determines acoustic functionality can be traced through this chain, and various criteria influencing the acoustic functionality can be identified. The source of the sound is the first instance of defining and influencing the acoustic; a periodic pattern coming out of a source (mouth) and in a certain direction, with certain energy and frequency. The medium is another crucial player, as the sound propagates in the material medium, it is influenced by the properties of it: For example, air is considered a good gas on one hand as it is non-dispersive, and signal shape stays the same through the transmission, but on the other hand, it is a significant filter for sound; or for instance, the influence of temperature humidity on the quality of the transfer for have been studied and quantified, as acoustic atmospheric absorption and attenuation coefficients. The obstacles in the surrounding environment play another crucial role. Upon reaching an obstacle, a door or another audience for instance, part of the sound intensity is reflected, part is transmitted through the obstacle, dissipated as heat or vibrations, part transmitted going through it, and part is scattered due to roughness of the surface for example. At the end of this transmission or filtration process, is the receiver; signals coming from out, can get modified, amplified, and so on, which is under 
the category of signal processing before comprehension. An example of how is that the transformation functions vary for one ear depending on the direction of the sound if it is coming from the front, top, or behind.

In the modelling of an acoustic transmission and filtration-for instance, to understand a social setting within an architectural setting, as in modelling of the historical case of the Forum Romanum [61,62]—one has to consider different factors in each of these mediums of transmission and simulate the transmission and filtration processes that could in principle occur. In such digital acoustic simulations of a space, one can also divide these mediums of transmission into three different levels: The microscopic or the molecular level; the mesoscopic or the individuals and subjects, and the macroscopic level of buildings and infrastructures. In each of these levels, one can apply empirical data, such as the environmental factors influencing the acoustic transmission of air at the micro level. At the meso level, the individual behaviour, crowd density, and so on can be considered in the model, while at the larger infrastructure such as building and architecture, one can think that architecture that is designed for acoustic events needs to gather the right amount of people, and orient them toward the acoustic source. Here, materiality of all the transmission mediums plays a crucial role on the final transmission, but not only as acoustic filtering on micro or meso material level, as in if the walls are from wood or concrete, but also at the level of infrastructure, as in how things are arranged in the macro scale.

The propagation, the diffusion or the filtration of the sound waves through the air molecules, the obstacles, and the corridors, occurs in a material sense, even though the transmission carries symbolic information.

\subsection{Filtering Architecture}

Architecture has traditionally being considered as a static system, often seen as mere containers or shelters, which once erected, are supposed to be stable in both time and space. Newer approaches highlight a so-called operative concept of architecture which, derived from media theory, focuses on the performative aspects of architectures [63-66]. One investigates the way buildings work rather than what they represent; how they generate certain environmental conditions; or how they not only accommodate but evoke, channel, regulate, or filter streams of people, things, or substances running through them. In this regard, one can see how buildings operate as filters, realising acts of selections and separations through a system of interacting architectural elements such as walls, doors, barriers, or corridors. The following paragraphs explore two specific examples of filtering architectures: Filtering people in railway stations; and filtering energy in membrane architecture.

In the 1870s German architects started a debate on how new railway stations should be constructed in order to handle the increasing amounts of travellers in a quick and smooth way. The railway engineer Franz Baltzer published an article in 1893 with the pragmatic title Ticket Control and Platform Barriers at Railway Stations [67]. Due to a high volume of traffic, a lot of travellers, as well as their accompanying farewellers, congested the platforms, which hindered the train service and endangered the station's safety. Baltzer proposed a new rule that would allow only people who actually used the trains and who possessed a valid ticket to enter the waiting rooms and the platforms. The implemented system allowed for guiding, examining, and separating the people streaming through the station according to their status as legitimate travellers, as paying company or as persons not being allowed to enter the station. To Baltzer, this seemed to be mainly an architectural task. He presented suggestions for altering railway stations so that they functioned as efficient architectural filtering systems (Figure 7 top). Ideally, they would be running automatically-meaning with minimal staff, costs, and reconstructing efforts. Outgoing travellers and incoming passengers all would need to pass through a checkpoint, and the whole building would be carefully arranged around this central check-point with every alternative entering point being blocked off via walls, barriers, and locked doors. What seems to be a quite manageable architectural task for newly-built stations proved to be rather intricate for already existing stations. Channelling and filtering the stream of travellers was further complicated when there were 
different circulations of arriving, departing, and transferring passengers. For instance, architects would have to consider the different facilities passed by the traveller, and decide whether the already existing restaurants or toilets were to be located before or after the checkpoint. Moreover, stations as time-critical systems were operating on rather complex schedules with minimum tolerance, and clogging the checkpoints with waiting people presented a certain risk factor. In the case of bigger stations, one can imagine that remodelling of this dynamic system into a filtering system could be a challenging organizational task. It is a matter of arranging architectural elements in space in order to generate controlled flows and selective passages via access control and the binary filtering logic of "pass" or "don't pass". Depending on their respective placements, regulating effects emerge. Some architects used the terms "flows", "currents", and "circulations" when contemplating on ideal layouts and arranging its spatial components. Eventually, all these references were used in order to understand and design railway stations as effectively running filtering systems.

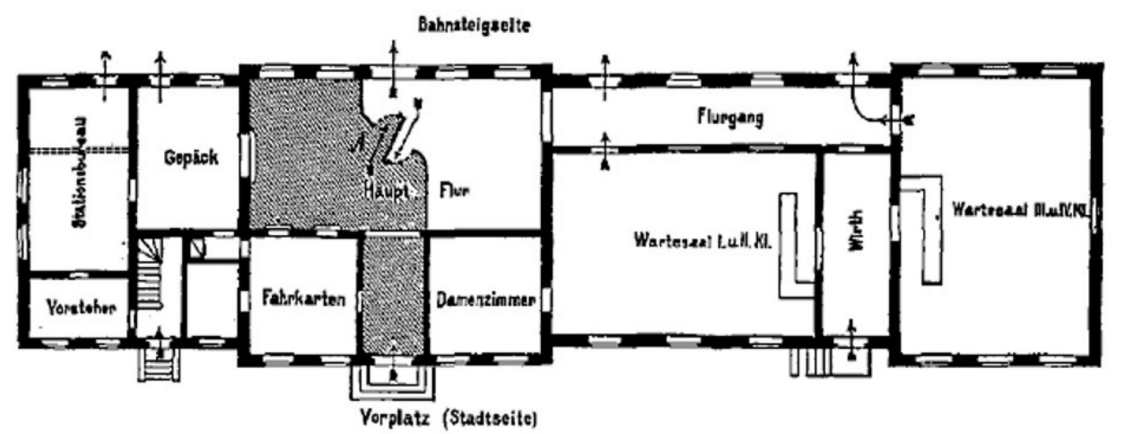

Empfangsgebäude einer Zwi chenftation mit im Eingangsflur befindlicher Bahniteigiperres\%).
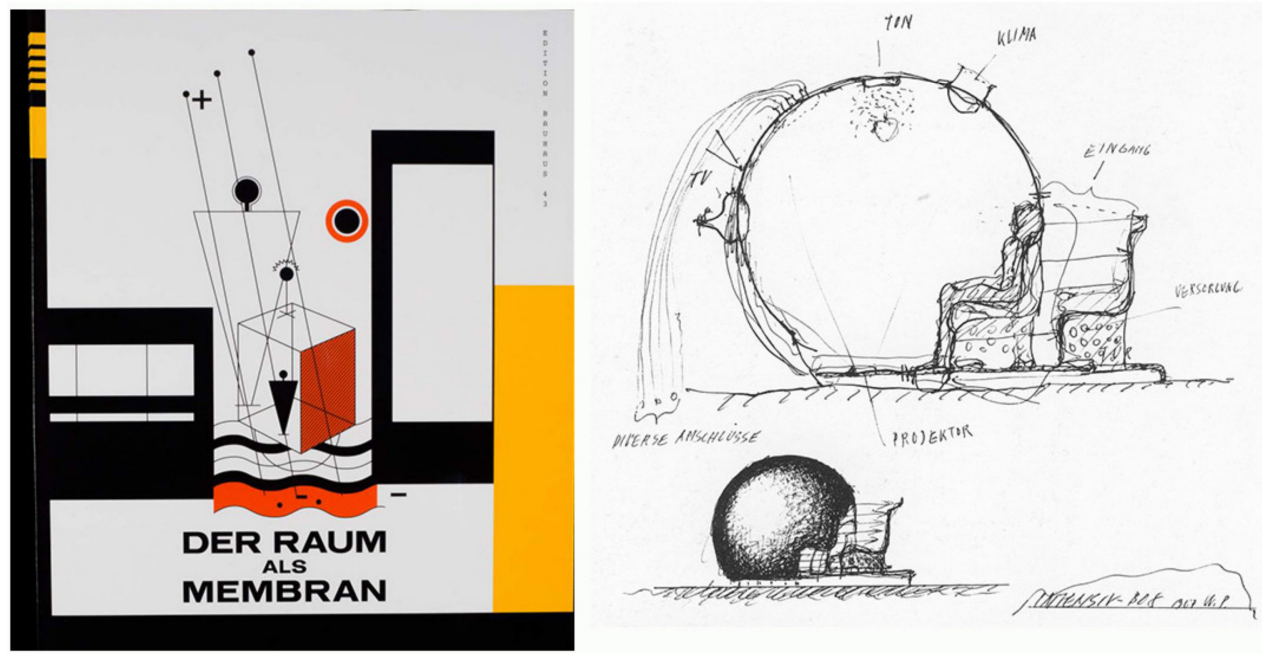

Figure 7. Filtering Architectures. Top: Flows in railway stations 1983. The top Image depicts Baltzer's proposed layout for small new-built stations in 1983, which would filter out the crowd; travellers would purchase their tickets, leave their bags at the baggage counter, and pass through a checkpoint, while anyone without a valid ticket would be filtered out of the platforms (image adapted from [67], (C) 2020 Zentral- und Landesbibliothek Berlin). The image on the bottom-left is the cover of Siegfried Ebeling book Space as Membrane, giving a less static/passive impression of architecture, as a transient medium regulating different forms of flow in and out (image adapted from [68], (C)Architectural Association Inc.). The image on the right shows Walter Pichler sketches of the "Intensivbox", that provides a filtered experience for the subject that slides into it, one in a series of work in 1967 where he criticized the pervasive presence of media (image credit: Walter Pichler, Intensiv-Box, 1967).

In 1926, the Bauhaus-student Siegfried Ebeling wrote an essay in which he introduced a new concept of architecture that he called Space as Membrane [68], and opposed it to what he considered 
the obsolete idea of space as a mere shell. In his small book, he elaborated on what future buildings should be capable of in terms of certain functions and performances. With what he called "biological architecture" [68] p. 19, he redefined the wall—traditionally being seen as a load-bearing, massive, and impenetrable element-as a three-dimensional semipermeable membrane or skin. Its porosity was not achieved by a mere adding of windows and thereby physically penetrating them, but by transforming walls into filtering devices. The cover of the book (Figure 7 bottom-left), shows in an abstract fashion how he conceived the building as a transient medium between the individual and his or her environment, permeable for different forms of electromagnetic spectrum that by penetrating the building would affect its interior in terms of natural and artificial light conditions, air, temperature, ventilation, and air pressure. The specific design of the wall openings would produce a "filtered stream of light" that is being "automatically regulated" [68] p. 36. Ebeling noted that his active, adaptive, and automatic architecture would not be a result of putting up a set of apparatuses like radiators, lamps, or blow fans, but to turn the building itself into some sort of biological system that reacts to surrounding conditions. His membrane building was meant to adapt to the climatic conditions of its specific location, and the house could become its own energy source, converting exterior radiation into usable energy, intensifying and optimizing the individual's physical and psychological experience of the space he or she is living in. As an architect, he was not so much interested in the membrane as a material but what he considered its biological functioning. Transferring its performance to architecture turns buildings into "responsive, active systems" [69] introducing forms of agency and self-regulation into architecture.

Such permeable membrane or filter understandings of architecture can be also seen in the work of many artists and architects during the 1960s. Walter Pichler have experimented with this operative and filtering aspect of space in many of his 1967 works, such as the "TV Helmet/Portable Living Room", the "Small Room", or the pneumatic "Intensive Box", which exhibits openings that control climatic conditions as well as the sound and vision the person inside is exposed to, replacing the outside reality with a filtered one (Figure 7 bottom-right).

In these lights, one can see that filtering operations of the architecture seem to make way for some rather innovative architectural concepts and projects, organizing functional buildings based on their central operations, as in the case of railway stations, or rethinking architecture in terms of ecology, climate, and energy, as in Ebeling's case.

\subsection{Informational Filters; Data Science}

Today, it is not only in the natural sciences and economy, but also in linguistics, sociology, cultural studies, etc., that the presence of the words data, big data, data analysis, machine learning, and so on are becoming more and more of a trend. From social media to the internet of things, data analysis and data science are integral parts of many of today's technologies. One simple way to describe data science is the methods and processes of analysing a set of data and extracting knowledge or predictive trends out of it.

As a common denominator underlying today's data science, filters and filtering operations lie at the core of every stage of the process: In the very first steps of collecting the data; organizing and cleaning of the data; understanding the metadata and data profiling; transforming into useful format; integration, mapping, stitching; analysing, making sense of it, and final interpretation of the results to find a pattern, solve a certain problem, or predict certain phenomena amongst others [70-73].

To reflect on filter and filtration process through all these steps, the following will explore an example of an imaginary case where a medical institute or insurance company runs a public survey to gain insight into certain aspects of smoking, may it be for prevention, health inquiries, or targeted advertisement, either to find a certain pattern, to validate a hypothesis on smoking habits, or to render a prediction.

In this case, the first step would be to collect the relevant data such as participants' names, age, address, life-style, smoking habits, and so on. Already here, at this very basic act of collecting the data, 
the first filtering occurs on the basis of defining the survey criteria and relevant targets, and designing the questionnaires; what is being taken as the input or raw data?; a certain region?; certain age group?; or is the focus gender-specific?

In order to do a proper analysis of the data, the collected data needs to be as homogenous as possible. The collected data-sets might contain errors, inconsistencies, or wrong entries that need to be assessed. These errors could be of various nature: Duplicates; entries in different languages; inconsistent postal codes; false birth dates; representation problems like order of family and surname; typos or random wrong entries, and so on, which need to be detected and fixed accordingly. This so-called cleaning of the collected data is in essence a filtering operation; data with certain features gets selected in, or weeded out, or classified into the relevant category.

Big part of data cleaning is about following and finding certain strategies to facilitate and automatize this process of making the dataset homogeneous and more processable, and is achieved through algorithms and processes that can be executed by humans or machines. The refining strategies can be simply reducing the data matrix by rational of how the data should look or be presented, for instance, a set of internal or external linked rules; common sense like removing duplicates; or based on data type in the programming language. It can also be based on the idea of what the data should be consisting of: For instance, based on certain assumptions about an objective fact, like a German postal code has 5 digits (rule-based corrections and detecting a violation), or about a prior secured knowledge, like no one alive is "230" years old, and most probably that entry contains an error (semantic and syntactic pattern verification and enforcement). The refining can also be some statistical or quantitative algorithms that detect statistical outliers, as in one person in a list of thousand participants who smokes three packs a day; or detect conflicting values, as in if the "age" entry shows 27 , while the "born in" shows 1983. There is not an apply-to-all solution to meet the challenges of data cleaning. There are a variety of tools and strategies available which, combined with experience, can help this tentative process gradually going forward, and checking if this or that strategy works or not.

In the next analysis step, the already cleaned organized data set is subjected to various sorts of algorithms to deduce a certain pattern and trend, validate a hypothesis, or reveal new insights. At the first level, the cleaned data can bear and reveal an obvious pattern; for instance, no one below 10 is smoking. However, more often than not, the big data analysis is about finding the correlations that are not obvious at first glance. On one level, the filtering operations can help to check the validity of a certain assumption, for instance, confirming the hypothesis that younger smokers are more prone to change to electronic cigarettes. On another level, certain algorithms run through a big data-set can suggest a hidden correlation without a prior hypothesis; e.g., single males age 30-40 seem to have a higher chance of quitting smoking after getting a pet. However, the majority of today's data science is more of a "grey box", as opposed to a black-box without any pre-assumed model or hunch.

The filtering aspect of data science does not stop here. Depending on the final goal, may it be to find patterns, validate a hypothesis, or predict a certain trend, the result of the analysis can further serve as the new filter criteria for the next step of action; for instance, classifying a certain group into the high-risk category charged with a higher insurance fee.

It worth emphasizing that these steps were followed in linear manner for the sake of clarity, and in reality, the process is more of an iterative nature; going back and forth in between as, for example, the result of an analysis can be put into action to serve as the new cleaning criteria (new filter) and so on.

One notable aspect here is that the Informational filters become time-critical. On one hand, the function and efficiency of the system depends on time; the more time you spend on cleaning and filtering (bigger data, finer data, more accurate data, etc.), the better results you might get. On the other hand, time has cost, and you would need more processing time, and have to try to simplify and automatize more by delegating these tasks as much as possible to the machine. However, the more crucial aspect is that, on more data, and on a broader and more diverse range of data-sets the filter (algorithm) runs, the better it gets at filtering. It either gets modified and more efficient by the constant search and devise of the data scientist, or the filter modifies itself over time as the machine "learns" 
and "gets better" at cleaning, analysing, and finding patterns, and eventually does a better job, after each new "experience" it gains.

At first glance, informational filters seem to be distinguished from most of the formerly discussed filters, as more symbolic (alphanumeric, code, etc.). However, images that are used for describing filtering are patterns and flows, and are talked about as if they were material things (blocking flows, partitioning, collecting, cleaning, mapping, matching). Besides, one cannot neglect the materiality of the hardware that back this seemingly symbolic operation.

Nonetheless, these informational filters are about meanings; they are symbolical, dealing with symbolic things on a symbolic level. On one hand, defining and changing different criteria and specificity of the filtering operation becomes easier, for instance, tuning the "filter-mesh" or the tolerated threshold for the accuracy of the result. On the other hand, the result of the filtering operation would have a broader impact. Although data cleaning is there to make the data processable, there is an element of producing the data in the process filtering and reducing it. Tools here are algorithms, as a set of rules, and rule-making that translates into and becomes producing through differentiation. This itself would set-up new criteria and new rules for next filtering and so on. Hence, the simple separatory or selective aspect of the filter producing differences, can take another tone here, and be expressed as a "validation" or "discrimination", as it is not just any separating process, but bears meaning and symbolically valuable decisions (e.g., insurance or loan credits). Although filtering algorithms are dealing with symbolic things on a symbolic level, as Yuk Hui argues in his book "The existence of digital objects", they define the realities of our material world [74].

\subsection{Moderation: On Content, Medium, and Human Filters}

An increasing amount of everyday information and knowledge are becoming more and more the products of filtering operations and filter algorithms that are not necessarily always understood as such. From the world of the internet and content production, suggestion, and moderation; to artificial intelligence, cryptography, and cyber security; to insurance policies, health care, and bio-politics, the informational filters are progressively becoming a crucial determining factor of today's life.

The effect of the informational filter is already visible from algorithms and data processes which are creating "filter bubbles" in news, social media, identities, and so on [4,5,75]. Even more alarmingly so, is the extent of the data surveillance and the piggybacking surveillance capitalism that produces and tabs into the streams of data from actions, experiences, emotions, and lives, and datafy them into categories and predictive systems, minimizing the uncertainty on the one hand, and on the other hand, shaping and controlling the realities of economies, social existence, and personal lives and cores [76].

From a media theoretical and semiotic perspective, the significance of this filter aspect of media is neither new nor trivial. Philosopher Jean Baudrillard, in his 1981 book Simulacra and Simulation, has pondered on questions of reality, symbols, culture, media, and their interrelations. He paints the relation of media and life as "a blending, a viral, endemic, chronic, alarming presence of the medium, without the possibility of isolating the effects", and points out the media's "induction" and "infiltration" to the point of a "dissolution" of medium and life into each other [77]. In this sense, "the filtered" of today's informational filter can translate to "the mediated", and "the mediated" into "the filtered".

As discussed before, the inherently selective and discriminatory aspect of the filter phenomena can translate into a pathological dimension (filter bias), but the questionable effects do not stop there. Segregation into fortified internally consensus circles (filter bubbles); a collective belief in the predictive powers of an in essence simplified model and forgetting the significance of deviations and disruptions (filter promises); getting blindly trapped in a rigid local optimum within a vast landscape of hills and valleys of possibilities, and the consequent self-fulfilling prophecies (filter trap), are just few of the other repercussions of the informational filter and it's symbolic significance.

All of these open up the question of power. From the "Archive Fever" of Derrida, to the "Surveillance Capitalism" of Zuboff, the discussions around the power to knowledge, epistemic justice, and rights, were built around the questions of who knows, who decides who knows, and what they 
can know [76,78]. These decisions on who has access to what adds another dimension (filter powers) to the set of the filter repercussions.

The lack of access or understanding of the black or grey boxes that define the reality of these mediated content and bubbles, might suggest a purely algorithmic view of this filtration system. The assumption that the algorithm, the tools, the machine learning. and the AI can have an "agency" of their own, is not as farfetched as it sounds. However, this view still overlooks or underestimates the extent to which the human agency plays a role in these processes, at least not in its current stage.

One instance of the human agency within these filters, are human internet-filters, or as officially called "Content Moderators". These are real people who are sitting in offices and scanning the internet for un-desired content, as in pornographic, violent, offensive, racist content, etc., and by following and applying a set of pre-set rules and their common sense, make a decision to remove content [79-81]. This is not only relevant, showing the human agency as a crucial factor in informational filter, as an example to counter the myth of purely algorithmic moderation, but also it is relevant to the rationale of this work, exploring filters of different types and scales and forming different realms. Here, there is the human cognitive system operating as the filter. It is not so much of a surprise, when the "human" filter there gets exhausted, some even get traumatised, and eventually the "filter" has to be "disposed of" and "replaced".

\subsection{Impact Assessment}

There is a range of different types of methods that can make up an impact assessment, that requires various elements of filtration processes. These include Responsible Research and Innovation (RRI) monitoring models and integrating Key Performance Indicators (KPIs), which have been used as a way of integrating RRI in science and technology $[82,83]$. RRI offers an added value of selecting and classifying research and innovation (R\&I) process dimensions to ensure desirable and acceptable research and innovation outcomes [84,85].

Furthermore, RRI as a systemic and operative model can draw on impact assessment to proactively move forward innovation policies and strategies towards more sustainable and responsible versions. To conduct R\&I activities "responsibly" and "sustainably" for a certain organisation, research and innovation process dimensions should be tailor-designed so as to make RRI an intrinsic part of R\&I activities. This requires chains of action and target setting to advance in RRI implementation levels [86].

Within the same lines, UN Sustainable Development Goals (SDGs) are an established stream of goals and targets that can be achieved by gearing up impact assessment practices [87]. SDG-related assessment initiatives tend to encourage societal actors to work together to better align science and technology and its outcomes with the values, needs, and expectations of society. SDGs, as a target-oriented term, are therefore crucial for the future and foresight activities.

To address grand challenges, an entity identifies the priority SDG targets through a filtering process, namely the process of principled prioritization to assist in integrating SDGs into the entity processes. This filtration deepens understanding of whether and how prioritised SDGs lead to societal, democratic, scientific, and economic benefits.

In a similar vein, in materiality assessment as well as in environmental, social, and corporate governance (ESG), one can utilize such filters to weigh the materiality of ESG issues, enable comparison of material issues, and perform benchmarking to identify gaps and leadership opportunities to ensure defining strategies in the right way.

To summarize, much of the literature views principled prioritization as a necessary complement to impact assessment. Thus, the filter to identify principled prioritization aims at providing social, environmental, scientific, and economic benefits. These filters are useful for mitigating risks and strengthening strategic planning. Taking such filtering models into account will help science and technology and innovation to increase their relevance and make optimal use of their established strengths. Furthermore, to redress knowledge gaps about the benefits of social-oriented terms, e.g., RRI, 
SDGs, and ESG in practice, the assessment practices calls for a greater understanding of different forms and practices of filter.

\section{Analysis Towards an Active Filter Model}

The last chapter portrays a diverse set of examples across a wide range of fields and scales, that deal with and discuss some type of filter or filtering phenomena in their work. By reflecting on some attributes of these diverse studied cases from an interdisciplinary perspective, in this chapter, we try to cultivate and frame a more comprehensive understanding of filter phenomena as the basis for a novel Active Filter Model.

\subsection{Filtering; a Separation Process, a Differentiation Process}

On the most basic level, filtering is a separating process that produces differences. This differentiation process can be manifested as selection, reduction, or classification.

Selection can be thought of as when something (of interest, of value etc.) is separated and brought out of a bigger system. The target-oriented, selective meshes of the filter-feeder tunicates can be seen as the example of selection, where the desired food particles of a certain size get trapped and accumulate.

Reduction is the case where the undesired is separated out of a system, reducing it to a purer desired state. The focus of interest here is signification by reduction. The chemical purification processes to get clean water or high karat gold; the case of the spider where the filter process, amongst others, can be described as the omitting of background noise; or the case of the reduction of a big data set through data cleaning filtration processes, are all examples of this instance of separation.

Separation can also occur as sorting or classification. Here, the separation act of Filter produces a certain order by separation elements of a system into different categories or classes. Apparent examples of this would be the informational filters of the data science case that recognize and categorize data according to defined criteria such as "male", "female", or others, or the case of the spider, where the filtration result in the calcification of the surrounding vibration into different categories of prey, friend, and foes.

There is not a clear-cut difference between these expressions of separation in filtering, but more of a shift of focus. In all these expressions, we argue, the separation is a process of differentiation that produces significance.

\subsection{Filtering; Systemic and Operative}

We don't consider filters as mere objects, but operative systems.

From a media theoretical point, there is an ecological aspect that goes along with these filters, rendering a systemic nature to filters; composed of different elements in interrelation with each other and their surroundings. Filters are systemic, and not mere objects; understanding the phenomena needs a shift from objects to systems.

Moreover, filters cannot be fully understood in their passive noun, object form. It is not only necessary to look at different elements and interrelations within a system, but more than that, there are chains of operations that need to be taken into consideration.

In current discourses within Media Theory or Cultural Techniques (Kulturtechniken), there is a paradigmatic shift of the focus from objects, devices, and nouns to chains of operations [88-90]. Our understanding of filters, in this model, requires a similar shift from taking the focus from the filter as an object, article, or device to the filter operations. To think "filter" is to think "filtering". As systems, filters are operative.

Besides, upon taking this systemic view and considering filters as open systems, a critical question arises: What does the system entail? What is part of a filter system, and what is not? The operative aspect becomes relevant here, as the filtering event itself can be the crucial criteria in order to draw this line. If an element is necessary for the filtering operation and function, it belongs to the filter system, and if not, it doesn't. To understand the filtering system as a whole requires one to shift the 
perspective and analyse the different filtering operations in play within specific boundaries. The term "event-based boundaries" seems a fitting concept here.

To get a more tangible understanding of the systemic and operative aspects, it might help to recap these aspects of the filter phenomena in some of the case studies.

Filter architecture of the Tunicate is a good example of recognizing this systemic and operative nature. In the case of the filter-feeder tunicate, we emphasized that the filtration cannot be fully understood by taking the individual nets and meshes, or even focusing on the bigger structure like the inlet-filters or the food-concentration-filter, or even the filter-house of the animal as a whole. The interrelation of different elements such as channels, pressure potentials, tail movements, water flows, accumulation nets, and so on, are crucial to understanding the phenomena. As discussed, biologists have attempted to describe animal-built structures in relation to the animal, as in the extended phenotype of Dawkins [45] or the extended physiology of Turner [46]. Turner writes: "There is a tangible boundary separating the organism from the environment, although seemingly solid, is an active permeable boundary, allowing a steady stream of matter and energy to pass continuously through" [46] p. 4. Expanding on Turner, we argue that these boundaries can sometimes become even more blurry, to a point that one cannot claim a functional division between the animal and its structure, as both are crucial parts of the filtering system. This also shows the significance of the paradigmatic shift of the focus from the objects (animal and the filter house) to the operations (undulating, pumping, circulating, accumulating, filtering). The operativity of the dynamic structures of both living and non-living can be described by understanding the system in terms of this extension of physiological operation to the "dead" structures and blurring the boundaries of the organism. This operative aspect takes a central role in our understanding of the system. Not only does this understanding dissolve the divide between the animal and structure, but more than that, the operation (continuous filtering) is the very thing that maintains the system, as the structure collapses when it is not in operation. The whole system is structurally and materially active and operating.

Similarly, the mechanosensing of the spider can only be understood and analysed by regarding the system as a whole: The slits; the epicuticle membrane; the nerve cell and neural paths; the lyriform organ; the leg joints; the animal as a whole; plus, the underlying leaves; the wind; even temperature influencing the sensitivity of the filter material and so on. Here again, to have a better understanding of the mechanosensing of the spider as a filter system, not only the systemic nature and the environmental interrelations need to be considered, but also the chains of operation need to be addressed. Something moves the leaf; which vibrates the leg's joints; the tarsus moves; hits the pad; compresses the slits; the vibration of microslits is translated into action potential; neurons are fired; decision is made; spider moves and eats the cockroach.

The systemic and operative view of the phenomena also gives a better understanding of the different manifestation of the filtering phenomena. On every level of the system there are structures that render detectable and non-detectable vibrations, filtering out what is detectable from all the other vibrations in their surroundings (for instance filtering out the background noise or the specific stance of the spider on the leaf defining the sensitivity of the filter system). This separating and selecting the useful from the useless information is in play at one level, while later on and on other levels, filtering operation manifests as classification, splitting up vibrational input into different categories, classifying them as what the spider perceives as "wind", "prey", "other spider", and so on.

Furthermore, a system of one slit with its epicuticle membrane and underlying nerve; a set of slits with different sizes and arrangements; or the impact of the spider's specific stance on the signal and the sensitivity of the filter system, each contribute to different aspects of filtering operation at different scales. Thus, they can be demarcated within an assigned boundary of interest and studied as a system or subsystem accordingly; the event-based boundaries.

In the case of graphene oxide nanosheets such as chemosensors or pathogen inhibitors, the selector is more than the graphene oxide sheet, neither is it the sulphated end of the dendritic branches 
stemming out of the 2D plane. It is systemic and operative as the filtration process becomes meaningful through certain surface functionalities, within a medium, and in regard to the specific bacteria or virus.

In the case of informational filters of data science, what comprises the filter system is this chain of operations through different phases of the process that need to be followed; data collection, data cleaning, integration, analysis, interpretation, and so on.

The systemic and operative aspect of filter phenomena is also evident in other case studies, such as in the attempt to model the material structure and functionality of the acoustic transmission systems through all the different micro, meso, and macro levels; or the operativity of architecture as filtering people or energy; or in the world of media or internet content, where a colossal amount of interrelations and operations, carried out by algorithms and/or humans, constitute the operative filter system.

The extent and scope of the systemic and operative nature varies from case to case; for instance, the kitchen sieve, as a physical filter, might not have the complexities of the tunicate filter-house. Nonetheless, keeping such a systemic and operative view of the phenomena helps to have a more holistic understanding of the phenomena, occurring within the broader dynamic event-base boundaries of a system of actors and operations.

\subsection{Filtering and the Ecology it Builds; Performativity}

The systemic and operative aspect signify a procedural aspect. We emphasize how this procedural aspect can create the filter domains or affect the filter or filtering operation.

Filtering Creates Filter Domains. The filtering operation, the action of what we point to as "filter", creates the filter domains in different ways.

First, the most familiar one, addresses cases where the filtering structure is set up and operates. Taking activated charcoal, for instance, only when one brings it into the medium (water) does the charcoal start separating dirt particles, producing cleaner water in the process. In the case of the spider, with a slight change of position or shifting into a more sensitive stance, a "filtering pose", the spider can alleviate the transmission and processing of the vibrations and optimize the filter experience. In the case of the graphene oxide sheets, talking about the 2D structure as a filter makes sense only within the right medium (in chemosensor application) or in contact with the specific virus (in pathogen inhibition application).

The second mode would apply when the filtering structure only exists because of its filtering operation. The filter-house of the tunicate, for instance, needs to be in constant operation so that the water flows and pressure differentials are sustained. Otherwise the structure would lose its integrity and collapse, thereby also bringing the filtration process to an end. Many of the informational filters have the same ontological mode.

A peculiar, third, mode is when there is no filter without the process of filtering; no filtering agent to be identified before the filtering process starts off. An apparent example of this would be the case of phase separation (oil-vinegar mix) or self-organization of the hydrophilic and hydrophobic macromolecules resulting in the case of bio-membrane like giant vesicles. The very act of separation and self-assembly due to specific physicochemical properties creates the separating boundary.

Hence, Filtering creates Filter domains, building a dynamic ecology, beyond mere parts or simple interrelations.

Filtering Affects Filter. The process of filtering has effects that alter filters and the consequent filtering operations. This phenomenon can be approached and understood from two different perspectives: Spatial and temporal.

In filters that work through semipermeability or adsorption, particles that don't pass through or are adsorbed accumulate over time. This can in some cases hinder the passing through or further adsorption, thus "clogging" the filter and stopping the filtering operation. In other cases, a phenomenon occurs that is called "filter cake", which can improve the filtration process. Starting from an initial point, adsorption of more and more particles creates a filter cake that acts as an even finer mesh "enhancing" further adsorption and filtration process. 
Filtering affects the filter; the tunicate filter house gets "clogged" and needs to be "replaced", or in the case of human content moderators, the traumas of the job can "exhaust" the mind to the point of therapy or early "retirement" of the human filters. Filter gets "clogged", "blocked, "filled", "covered", "consumed", sometimes need to be "disposed", "replaced", or "cleaned", but also sometimes gets, "better", "smoother", or "refined".

The process of "filtering affecting the filter" is not limited to spatial sense as in the case of the activated charcoal and the clogging. The "filtering affecting the filter" can also be described from a temporal perspective, rendering a time-criticality to Filter.

The data filter, for example, can get "better" over time as the algorithm is refined over the course of its performance, leading to a more precise or optimized algorithm and process, for example in machine learning. They can also modify the process itself, changing the "mesh" of the filter, as in changing its specificity, for instance. This adaptation aspect is not always a positive thing, as discussed before, the process can also lead to feed-back loops that accumulate certain features, that become pathological, accounting for local optimums and self-fulfilling prophecies.

This ecology aspect of the filter can be traced back to the earlier discussed systemic and operative aspects of the phenomena, and be based within the concept of "Performativity" [91-93]. Performativity is a concept that is increasingly gaining ground in various fields such as linguistics, gender studies, anthropology, cultural studies, economics, and so on, and can be thought of as an emphasis on the performative nature of phenomena, blurring the boundaries between "what something is" and "what it does" [91-93]. The systemic nature of filters spotlights the interrelations and interactives of the systems, while the operative aspect brings the attention to the dynamism of the systems, which would further emphasize the event-base boundaries of the system. The philosopher Karen Barad term "intra-activity" seems fitting to describe the situation of filter [94]. Here, and within these various ways that "filtering affects the filter", there is an element of performativity in a sense that the filtering, within an intra-activity context, is building its ecology; an adaptation, a co-evolution of actors and contexts.

\subsection{Filtering, a Negentropic Process}

Upon filtering, differences are generated, and thus a certain sense of "order" is produced. In this sense, filtering can be considered a negentropic process.

The purification of water in the case of activated charcoal; the separation and accumulation of food in the Tunicate case; the very sustenance of life in the case of the cell membrane; the sense making of spider from its material mechanosensing; the classifications of the data science and moderation of content; the regulations of peoples flow in the architecture of the train stations, all point out to producing some sort of order, and decreasing the entropy of something.

In statistical mechanics and thermodynamics [95] entropy can be interpreted as an expression of disorder of a system, and is defined within a system and in relation to the outside. Still, an event might be increasing the entropy of a system within a certain boundary, while the same event might be negentropic if one draws the boundary lines differently, for instance broadening it to include other elements in, or according to a different context. These boundaries matter, and context matters in how to define these boundaries.

The notion of negentropy is understood as order producing, as in "negative entropy" [96-98]. The negentropy in the order producing Filter processes is also highly correlated to the context. Something can be seen as negentropic when considering one aspect, while the same process can be seen as increasing the entropy in another aspect. Airport security checks are a good analogy to see how the concept of negentropy is highly bonded to context. Looking at the people queuing behind the gate and people on the other side in the departure lounge; one can look at it from the view of socio-political context; it takes a population of people and separates them into two categories of "pass" or "take your shoes off", producing a new classificatory order, decreasing entropy. However, the same gate seen 
from a purely thermodynamic context, ordered lines of elements (people) turn into a more scattered distribution in the departure waiting lounge; increasing entropy.

Entropy within early information theory [99] is defined as the unit for information content. Here, information can be thought of as a characteristic of a medium of transfer that can be quantified, regardless of the exact content of the information. The entropy of a system in this sense is related to the lack of information about it. The higher the information content, the lower the entropy of the system. If information and meaning is produced by producing differences, entropy is lowered. Thus, also from this perspective, the informational filters discussed in data science and content moderation and so on, are negentropic difference-producing symbolic filters.

In the discourse of active matter, Menon proposes the filtering membrane as an example of active matter [13]. One of the key challenges in active matter research is the question of how to describe encoded material and the surrounding conditions as both a mechanical and an informational structure. This way of describing the functioning of Filter via the notion of entropy, or here negentropy, can be the link that combines a material perspective with a symbolic one, the organizational and the informational.

All these systemic, operative, performative, and negentropic views of the phenomena signify a temporal dimension of the process; filtering does not only entail selection or classification due to some material or symbolic characteristics, but also brings about a temporal differentiation of the state of the systems as in before and after. Thus, placing filter at the focal point of discussions around physics, chemistry and physiology of life, organization and information, material and symbolic activity, and the nature of nature.

\section{Conclusions and Open Perspectives}

The idea of the presented work originated from identifying a gap and a need for a comprehensive model of filter and filtration phenomena that would address the concept in its diversity of the use within various disciplines and realms of knowledge. The first step in approaching the problem was to recognize that the topic of Filter lends itself to an interdisciplinary approach as filter and filtration can be found as topic of research, analysis, and synthesis in a variety of disciplines and fields within physic, chemistry, biology, informatics, and social sciences, amongst others.

The overview of typology and commonalities of various filter phenomena within a range of diverse fields helped to have a better understanding of the initial research questions of: What is filter, and how can the activity of filter systems be described? This analysis led to synthesis of the proposed Active Filter Model, suggesting:

Filter cannot be assessed in terms of mere objects, defined by clear boundaries, but needs to be understood as a complex active system and in relation to the ecology it builds; signifying a systemic, operative, performative, and negentropic nature to the phenomena:

The active aspect of the filter phenomena, implies that it realizes different forms of selection, separation, reduction, and calcification processes of, for instance particles, waves, symbols etc. producing differences and significance. Hence, we can talk about a negentropic process; and consequently a sense of agency.

The systemic nature of the phenomena highlights that filter emerges as complex systems, with all the various involved elements and actors (bases, barriers, channels, flows, circulations, temperature, signifiers, gradients, inventories, thresholds, frequencies, pressures, etc.), and the complex interrelations and intra-actions within the ontologically relevant environment and contexts.

The operative aspect points out that a more comprehensive picture of the phenomena can be understood, not just through a snapshot of different elements and their interrelations within a system (synchronically), but by seeing the picture in its full dynamism (diachronically), through various chains of operations (compressions, attractions, repulsions, self-organization, hinderings, adaptation, separation, selection, accumulation, reduction, classification, regulation, and so on), that brings about filtration activity, which itself can realize further operations. 
The performative aspect of the filter phenomena, emphasizing on the ecology that it builds, expresses the interwoven aspects of being and becoming, and the co-evolving actors and contexts within an intra-activity relation.

In this light, one can open up some new questions and realms of inquiry that need further work and discussions. The answer to these might be beyond the scope of the paper, but the following is an extended perspective chapter that would briefly points out some of the relevance of these reflections in various research and practices. Throughout this chapter, the authors try to briefly open up some research questions from various fields of natural sciences, information philosophy, sustainability, etc., point out to how they relate to the theme of this work, and put forward a path through which the proposed Active Filter Model might shed light on some of these questions, or be a base for further sophistication of the model through these questions.

(1). If and how could this new understanding of Filter phenomena serve as a model to encroach the dichotomy of material and symbolic?

One of the distinct features of the Active Filter Model is that it was grounded in an analysis of a variety of filters and filtration systems operating on material, symbolic, or both dimensions.

One of the emerging questions in this light is about the characteristics of material and symbolic filters: What is the materiality of a symbolic filter processing, and how can material filters be described symbolically? Is there a fundamental difference between the two dimensions? Can they be understood as different qualities to the same phenomenon?

The case of spider mechanosensing, for instance, is relevant here; seen through these Active Filter Model lenses, it shows a filter system, comprised of, for the most parts, material operations which are primarily about and brings about symbolic meaning producing filtration. Moreover, the negentropic argument already opened up a new dimension into the questions regarding the material and symbolic dichotomies, the organization and information, that needs to be further investigated.

The proposed Active Filter Model, with its invitation to a systemic, operative, performative, and negentropic view of the filter phenomena, can be a prime starting ground upon which one starts to delve into these questions regarding the interrelation of materiality and symbolic aspects.

(2). If and how could this Active Filter Model relate to current discourse around the nature and relation of organization and Information?

The dual symbolic and material nature of the filter phenomena brings the discussions within our Active Filter Model close to the current discourses on the nature of information and organization, semiotics, and meaning producing material processes [100-104].

In his works on nature of information and emergence of semiotics from matter, the cognitive scientist and neuro-anthropologist Terrence Deacon starts from Shannon and Boltzmann and introduces three processes that are in play in regard to the information and organisation: Homeodynamic, morphodynamic, and teleodynamic processes, each emerged from the former one. In this view, Boltzmann is significant, as in how matter and energy are both in motion and conserved, merely transforming, and Shannon is relevant, as he gave a mediated notion of information, as neither matter nor energy. Built on these former understandings, he stresses the concept of constraints to explain what each of these three processes are about: Homeodynamic processes decrease constraint; morphodynamics increase constraints, reduce options, make more regular; and teleodynamic processes preserve constraints, maintain them once they are generated. In this view, he merges the organization and information in one organization-information paradigm, and thinks of information, as maintaining the relationships of aboutness in the world. From then on, he discusses the emergence of agency from this possibility of the stored information about the constraints [100-102].

In the Active Filter Model, the system is defined through event-based boundaries recognized through and realizing the filtering operation, which can correlate to emergence and preservation of the discussed Deacon's constraints as something crucial to the whole organization-information paradigm. 
The question here would be; if and how this view of the filter phenomena can contribute to further understanding of each of these constraints decreasing, constraint increasing, and constraints preserving processes, in information and thermodynamical organization sense.

(3). How can further concepts from thermodynamics be associated with this Active Model of the Filter phenomena?

The Maxwell demon was a way to express the impossibility of acting against the entropy principle of the thermodynamic second law, providing a rough sketch of the negentropic nature of semipermeable membrane activity. Entropy and free energy, or more generally, thermodynamics, has long been one of the leading paradigms in addressing the peculiar organisatory activity of material, and more recently the broader Active Matter discourse [13,19].

The negentropic argument here opens up a way to address both material and symbolic aspects of the filter phenomena through a thermodynamic term. As pointed out, this negentropic view emphasizes on the context-dependant order producing of filtering, and might be a fitting approach to bridge the gap between the symbolic and material dimensions on one hand, and on the other hand explore the temporal aspect of bringing about a before and after in the system.

A crucial question in this regard would be: How and in what way could thermodynamic concepts, beside and other than entropy, elucidate the filter phenomena and its relevance in the order-producing and meaning-producing discourse.

The argument here is not that the energy considerations are irrelevant, but that they might be insufficient to address the complexity of the observed reality through purely reductionist energy arguments. In the same way that quantum mechanics might not be a sufficient level of description of a system like a flying bird or swarm behaviour of bird flocks, here too one might have to think at the level of organization and structures, inducing the activities.

Argumentations along the formerly discussed lines of Deacon, for instance, are an attempt to look at the problems of thermodynamic organization and information, not merely through the strict entropy and thermodynamics' second law, but talk about other processes that can more authentically reflect the self-organization as a far and wide present reality of our world [100-104].

Dissymmetry, for instance, is sometimes thought of as a "counter" part of the second law of thermodynamics. While symmetry deals with an identicality of a system around a symmetry point, line, or plane, and asymmetry states an absence or lack of such point, dissymmetry emphazes on ubiquitous presence of partial, quasi, or broken symmetry in all scales of the universe $[105,106]$. Asymmetry, as complete absence, or presence of infinite symmetry, naturally tends toward stability, an equilibrium capable of bringing about effective symmetries. In an established symmetry, a partial or non-accidental break of symmetry can happen and complicate the formerly established equilibriums, rendering what is termed as dissymmetry. It has been argued that dissymmetry can be that activity-inducing nature that can bring about temporal before/after change of a system, for instance, in the bifurcation point of a far-from-equilibrium dissipative state leading to a new state of organization, structure, property, or self-regulation.

Dissymmetry, far-from-equilibrium thermodynamics and dissipative structures, self-organization processes, Teleodynamic processes, homeostasis, and so on, might relate to this paradigm of Filter in ways that would go beyond the reductionist energy arguments, and mutually enrich their understanding.

(4). If and how could this understanding of Filter phenomena shed light on material activity and agency beyond the dichotomy of mechanistic or vitalistic?

Following on these former questions, and echoing back to the discussion in the introduction and how various scholars described the semipermeable membranes as active, "un-dead", one can take the Active Filter Model and reflect on different dimensions of filter activity and agency, namely controlling and containing. 
First, the controlling, regulative aspect of filter agency, renders filter systems as a category of active matter that brings the "sensor" and "motor" in one, which brings about the controlling aspect of the agency as biased selector or classifier and so on.

Various biological sensors (such as sight, hearing, taste, etc.), are filtration operations (for electromagnetic filter, mechanosensing, chemosensing, respectively), the outcome of which comes together in a central processing system to make sense of the immediate environment (mapping) to predict the best viable course of action for the immediate future. Control systems can comprise a clear separation of sensor and actor systems, or as in the case of spider mechanosensing, they can have a blurrier boundary between the sensing and acting, leading to a more autonomous agent-like activity.

Filtering in these systems can be seen as more of a unified field of action that involves detecting, sensing a difference, and acting upon it; producing and processing differences, and realizing some form of organization and information as significant.

Systems with a more unified field of action can have a self-regulatory aspect, with negative feedback loops and homeostasis-like performances which are typical of life and biology. Biological sensors, in this sense, can be seen not as mere detectors (e.g., the photoreceptor in the eye, or the lyriform organ of spider leg), but as active systemic Filtering operations that merge the detection, processing, and action within one larger system (vision, or mechanosensing).

This highlights the second aspect of the filter activity and agency; the containment. On one hand, the formerly discussed event-based boundaries contain a system, rendering it into a semi-closure, while the performative and ecology building aspect, on the other hand, points to the open flux and communication with the rest of the world.

Hence, one further question would be; if and how this systemic and active model of Filter can be a ground upon which one sets off to investigate questions relating to controlling and containing within the dynamics of dissipative structures and dissymmetry organisations, that seem to be aspects crucial to emergence of agency $[105,106]$.

Moreover, the concept of function becomes another crucial aspect to be further investigated in these lights. The "functional" or design stance in biology—and at a higher level, the "intentional" stance—can be considered as situated within, and has evolved from, an evolutionary history and an ecology [104,107]; it comes from a lineage of memories of competencies that allowed the survival and replication of the functional trait, and it is interwoven within a network of dynamic interrelations; co-evolution of actors and contexts. Under these lights, the function and intentionality (or the unintentionality) of the filtering can be taken and discussed in two ways: Either as a post-biology phenomenon that can be utilized to move a system toward a certain goal, or as natural pre-biology processes of bifurcation that can give rise to self-organization, self-regulation, homeostasis and pseudo-agencies.

All of these would place the filter theme within all these current discourses of organization, information, function, and agency. Hence, the next question would be how this Active Matter perspective of Filter can relate to and address self-organization, homeostasis, autopoiesis, sympoiesis, bio-semiotics or semiopoiesis understanding of abiogenesis, life and biology.

(5). How could this Active Filter Model be a base for synthesis and design within the diverse engaged fields?

How can insights from the proposed model of filter as active systems be used as a new approach to synthesis, and develop novel integrative technologies, designs, and design approaches?

For instance, in water or air filtration, how to detach from the idea of the filter as an object or device and take the systemic, operative, and performative aspects seriously, to go beyond existing technologies and towards an innovative active water or air filtration system (for instance, inspired by the marine filter-feeders such as the one discussed in this work)?

At a larger scale, how can this model help to rethink architecture and build it in terms of this understanding of filtering, without reducing the filtering agent to the building's outermost layers of walls and windows (architectural membrane)? Rather, how can the whole structure be transformed 
into an active, regulative, and adaptive filtering system on different levels and scales? How to generate active filter architecture systems that integrate a wide range of criteria such as; regulation of energy, acoustics, air, climate, streams of people, objects, information, within buildings and urban architectures?

In regard to sensors, we addressed the mechanosensing of the spider as a material as well as a symbolic filter, where a sophisticated material system executes the main information processing at the periphery, and before it reaches the brain. The question here is what is the relation between sensor and filter? and how does it relate to the symbolic and material dimensions? More specifically, how this active and systemic understanding of the phenomena can help us to better articulate this relationship, and to think and design sensors which can filter and process more and more of the input data on material level, taking the weight off the symbolic machine such as the computer or a central nervous system: A highly selective and specific material symbolic sensors, where the filtering is regulated through material structure and properties, embedded in the material structure of the sensor itself.

Hence, another question would be: If and how can this active view of filter be situated and addressed within responsivity, adaptivity, and interactivity as novel paradigms in designing new sustainable material systems?

More broadly, how can the model be utilized as an analytical tool to re-investigate certain aspects within natural sciences, informatics, engineering, biology, linguistics, cultural history, informational philosophy etc., and provide basis for synthesis of new solutions, models, paradigms, and so on?

(6). How could this Active Model of Filter address some aspects of the responsibility and sustainability discourse?

One challenge is to take these aspects inherent to the filtering phenomena and rethink them in terms of responsibility and sustainability.

The contemporary discourse of responsible research and innovation states that scientific research and innovations have social, ethical, legal, economic, or political implications, and needs to be self-reflective and anticipate its effects on society and the environment. Similarly, research dealing with filter systems would then need to proceed with a high degree of conscious reflection and cautious anticipation.

As pointed out before, filtering as a separating operation-being a selection, classification, or reduction-implies an aspect of discrimination. Whether in personal or local bubbles as a consequence of algorithms of data science in media content, or within a chemical purification process, there seems to be an element of "bias" involved in these filter operations. This inherent bifurcation quality of filtering operations manifests themselves in many of today's challenges; from the filter bubbles, personalized news feeds, or data-driven insurance policies $[4,5,76]$, to a race to optimized functions through a fetish of material purity accounting to a major material sustainability [108]. It is crucial that the function and consequences of this separatory aspect be regularly noted and checked.

Moreover, the formerly discussed repercussions of the informational filter in the context of data science, content, or media become relevant in the responsibility discussions. Such understanding of the filter phenomena as presented in this work, can serve as a ground upon which the scholars can base their critical analysis and pathology of the pervasive data science and AI in every nook and cranny of today's lives. The "filter biases", "filter bubbles", "filter promises", "filter traps", "filter powers", and so on need to be addressed and investigated regularly and in all contexts, to develop a more comprehensive view of the filter phenomena, that includes but goes beyond the critic of the consequence of the final stage of the filtering (e.g., news bubble), and expand their analysis throughout various stances of the systems as well as various stages of the involved operations (as discussed in the informational filters). Such critical analysis, could synthesize concrete proposals for responsible implementation of corrective measures at the technical as well as the at the policy level.

In addition to that, in the design of filter systems of any sort, it is essential to take into account and ensure that the process and output of the filter is resilient to these unintended consequences. As the consequences of actions can be pushed to be easier to be misused unethically and irresponsibly, 
hence extra focus on resilience is indispensable to enable us to cope with disturbances and move to a more sustainable, responsible, and ethical output. For instance, the stakeholders and operations that embrace a systemic filter mindset and embed it within their strategies, designs, and decision-making will become more resilient in this sense.

Ultimately, within the responsibility discourse, one needs to be attentive of the systemic nature of filtering processes with all its operative actors to anticipate the consequences of their interrelations.

From the linear economy model of take-make-dispose and consequent waste management, to the more recent circular economy paradigm and dynamic understanding of behaviours, the sustainability discourse has come a long way $[109,110]$. The meta-analysis of the filtering phenomena within a variety of fields shows how a shift from an object oriented, isolated, and passive perception of a phenomena to a more systemic, operative, and performative understanding can provide a more comprehensive and integrative ground for analysis as well as synthesise endeavours. The proposed Active Filter Model can be a base, a precedent, for a similar new take on sustainability and expand on the recent development in the field [109,110]. This "meta-sustainability" discourse we are putting forward here suggests taking concepts, issues, and problems within the current sustainability discourse and rethinking them as a situated phenomenon embedded within a systemic and dynamic context. From a systemic perspective, see them as situated within an ecology of interrelations and interactions and intra-actions (synchronically); and from an operative and performative perspective, as situated within a history, and affecting and being affected by chains of operations (diachronically).

(7). How can the proposed Active Filter Model be further expanded to integrate other aspects of the phenomena?

We emphasized that the systemic and operative nature of filters needs to be acknowledged regardless of disciplinary specifications. However, it is essential to think how the topic can allow for integrating research that was not taken into account. Moreover, how various research that would not usually be associated explicitly with filters-from quantum mechanics and cosmology to cognitive science and information philosophy and so on-can be reflected upon and be addressed parallel to the proposed active understanding of Filter phenomena.

The proposed Active Filter Model can be a base and invitation for further exploration of the phenomena.

Author Contributions: The main body of this work is the result of the two years of collaborative interdisciplinary research of K.R. Investigating different filter materials, filter systems, and filter operations from a joint perspective of natural sciences and cultural history, and using the analysis to build a comprehensive active model of filter phenomena. E.Y. joined the project later on and complemented the work by bringing perspective from business, ethics, and Responsible Research and Innovation (RRI). The final piece is the work of K.R. reflecting on the result of this research and shaping them into a coherent manuscript. All authors have read and agreed to the published version of the manuscript.

Funding: The authors acknowledges the support of the Cluster of Excellence Image Knowledge Gestaltung an interdisciplinary laboratory, in Humboldt-Universität zu Berlin for the support during the research period, and the support of the Cluster of Excellence »Matters of Activity. Image Space Material « funded by the Deutsche Forschungsgemeinschaft (DFG, German Research Foundation) under Germany's Excellence Strategy - EXC 2025 -390648296 .

Acknowledgments: Authors would like to stress that Susanne Jany played a central role in the presented work, from the early ideation, analysis of the different case studies, and concept formulation and development of the model and, despite not being among the authors list, she is considered as an equal contributor to the work.

For most cases, the analysis was based on the preliminary contribution from various experts from different disciplines, within the related thematic workshop (see methodology section), or through personal discussions, as follows:

The Filter workshop was an interdisciplinary workshop organised by Khashayar Razghandi and Susanne Jany, within the research project in the priority area Active Matter of the Image Knowledge Gestaltung an interdisciplinary laboratory cluster of excellence in Humboldt-Universität zu Berlin, in September 2016.

Filter Feeder Larvacean Tunicates: as part of the disciplinary research project of the author, Khashayar Razghandi, within the "Active Matter" priority area, Image Knowledge Gestaltung an interdisciplinary laboratory cluster of excellence in Humboldt-Universität zu Berlin. 
Filtering, an operative aspect of Architecture: as part of the research project of Susanne Jany, "Active Matter" priority area, Image Knowledge Gestaltung an interdisciplinary laboratory cluster of excellence in Humboldt-Universität zu Berlin.

Filtering in cell membrane: presented by Roland Knorr, group leader of the research group Dynamics of Bio-Membranes, at the department of Theory \& Bio-Systems, Max Planck Institute of Colloids and Interfaces.

Filtering and Mechanosensing in spiders: presented by Yael Politi, former leader of the research group Biological chitin-based tools and sensors, at the Biomaterials department Biomaterials of Max Planck Institute of Colloids and Interfaces.

Filter, Material Structure and Functionality in Acoustic Transmission System: presented by M.A Sebastian Schwesinger, former PhD student of Department of Cultural History and Theory, Humboldt-Universität zu Berlin; and researcher of Image Knowledge Gestaltung an interdisciplinary laboratory cluster of excellence in Humboldt-Universität zu Berlin.

Filters, filtering and cleaning in data science: presented by Prof. Ziawasch Abedjan, former head of the BigDaMa, Institute of Software Engineering and Theoretical Computer Science, Technische Universität Berlin.

Filter, from an Active Matter, cultural history and media theory perspective: presented by Michael Friedman, mathematician and scholar of philosophy, and Karin Krauthausen, literary scholar and cultural theorist, both former researchers within the "Active Matter" priority area, Image Knowledge Gestaltung an interdisciplinary laboratory cluster of excellence in Humboldt-Universität zu Berlin.

Filter in Graphene Oxide Nano sensors and pathogen inhibitors: introduced by Mohammad Fardin Gholami, former PhD student of the Physics of Macromolecules group, Department of Physics, HU Berlin, and associate of Image Knowledge Gestaltung an interdisciplinary laboratory cluster of excellence in Humboldt-Universität zu Berlin.

Filter in Impact Assessment: introduced and analysed by Emad Yaghmaei as part of his research on business, ethics and RRI, in the Department of Values, Technology, and Innovation, Delft University of Technology, Delft, The Netherlands.

Author would like to acknowledge these contributions and thank the corresponding researchers for introduction of the research themes.

Conflicts of Interest: The authors declare no conflict of interest.

Other Ethics Statements: The authors declare no other ethics statement.

\section{References}

1. Paarmann, L.D. Design and Analysis of Analog Filters: A Signal Processing Perspective; Springer: Berlin, Germany, 2001; ISBN 0792373731.

2. Sparks, T.; Chase, G. Filters and Filtration Handbook; Elsevier BV: Amsterdam, The Netherlands, 2016.

3. Musoff, H.; Zarchan, P. Fundamentals of Kalman Filtering: A Practical Approach, 3rd ed.; American Institute of Aeronautics and Astronautics: Reston, VA, USA, 2009.

4. Pariser, E. The Filter Bubble: What the Internet Is Hiding from You; Penguin UK: London, UK, 2011.

5. Lanier, J. Who Owns the Future? Simon and Schuster: New York, NY, USA, 2014.

6. Ouahabi, A.; Depollier, C.; Simon, L.; Koume, D. Spectrum estimation from randomly sampled velocity data [LDV]. IEEE Trans. Instrum. Meas. 1998, 47, 1005-1012. [CrossRef]

7. Ouahabi, A. A review of wavelet denoising in medical imaging. In Proceedings of the 8th International Workshop on Systems, Signal Processing and their Applications (WoSSPA), Algiers, Algeria, 12-15 May 2013; pp. 19-26.

8. Singh, B.; Al-Haddad, K.; Chandra, A. A review of active filters for power quality improvement. IEEE Trans. Ind. Electron. 1999, 46, 960-971. [CrossRef]

9. Singh, B.; Rastgoufard, P.; Chandra, A.; Al-Haddad, K.; Singh, B. Design, simulation and implementation of three-pole/four-pole topologies for active filters. IEE Proc. Electr. Power Appl. 2004, 151, 467. [CrossRef]

10. Ge, P.; Liang, X.; Wang, J.; Zhao, C.; Gao, X.; Ding, Z. Optical Filter Designs for Multi-Color Visible Light Communication. IEEE Trans. Commun. 2018, 67, 2173-2187. [CrossRef]

11. Ganss-Puchstein, R.; Ruppel, C.; Stocker, H. Spectrum shaping SAW filters for high-bit-rate digital radio. IEEE Trans. Ultrason. Ferroelectr. Freq. Control 1988, 35, 673-684. [CrossRef] [PubMed]

12. Ruppel, C.C.W. Acoustic Wave Filter Technology-A Review. IEEE Trans. Ultrason. Ferroelectr. Freq. Control 2017, 64, 1390-1400. [CrossRef] [PubMed]

13. Menon, G.I. Active Matter. In Rheology of Complex Fluids; Krishnan, J.M., Deshpande, A.P., Kumar, P.S., Eds.; Springer: New York, NY, USA, 2010.

14. Grote, M.; Stadler, M. Membranes, Surfaces and Boundaries. In Interstices in the History of Science, Technology and Culture; Max-Planck-Inst. für Wissenschaftsgeschichte: Berlin, Germany, 2011. 
15. Grote, M. Membranes to Molecular Machines: Active Matter and the Remaking of Life; University of Chicago Press: Chicago, IL, USA, 2019.

16. Brandstetter, T. The Vitality of Membranes: Artificial Cells as Boundary Objects, In Membranes, Surfaces and Boundaries. In Interstices in the History of Science, Technology and Culture; Grote, M., Stadler, M., Eds.; Max-Planck-Inst. für Wissenschaftsgeschichte: Berlin, Germany, 2011.

17. Brandstetter, T. Life Beyond the Limits of Knowledge: Crystalline Life in the Popular Science of Desiderius Papp (1895-1993). Astrobiology 2012, 12, 951-957. [CrossRef] [PubMed]

18. Vicsek, T.; Czirok, A.; Ben-Jacob, E.; Cohen, I.; Shochet, O. Novel Type of Phase Transition in a System of Self-Driven Particles. Phys. Rev. Lett. 1995, 75, 1226-1229. [CrossRef]

19. Gholami, F.; Guiducci, L.; Yani, S.; Razghandi, K. Rethinking Active Matter. In Active Materials; Fratzl, P., Friedman, M., Krauthausen, K., Schäffner, W., Eds.; Berlin u.a. (De Gruyter), Buch \& Open Access: Berlin, Germany, 2020; in press.

20. Razghandi, K.; Turcaud, S.; Burgert, I. Hydro-Actuated Plant Devices. Nonlinear Elast. Hysteresis 2014, 171-200. [CrossRef]

21. Maxwell, J.C. Theory of Heat. In Text-Books of Science; Longmans, Green, and Co.: London, UK, 1872.

22. Fraser, R.; Otis, L. Metaphors of Invasion in Nineteenth-Century Literature, Science, and Politics; Johns Hopkins University Press: Baltimore, MD, USA, 1999.

23. Frei, M. Centrifugation basics. BioFiles 2011, 6, 4-5.

24. Rydberg, J. Solvent Extraction Principles and Practice, Revised and Expanded; CRC Press: Boca Raton, FL, USA, 2004.

25. Cuatrecasas, P.; Anfinsen, C.B. Affinity Chromatography. Annu. Rev. Biochem. 1971, 40, 259-278. [CrossRef] [PubMed]

26. Hale, A.J. The Manufacture of Chemicals by Electrolysis; Van Nostrand: New York, NY, USA, 1919.

27. Arnold, T.; Linke, D. Phase separation in the isolation and purification of membrane proteins. Biotechniques 2007, 43, 427-440. [CrossRef] [PubMed]

28. Ponec, V.; Knor, Z.; Cerny, S. Adsorption on Solids; Butterworth-Heinemann: Oxford, UK, 2018.

29. Bansal, R.C.; Goyal, M. Activated Carbon Adsorption; CRC Press: Boca Raton, FL, USA, 2005.

30. Sircar, S.; Golden, T.; Rao, M. Activated carbon for gas separation and storage. Carbon 1996, 34, 1-12. [CrossRef]

31. Bhatnagar, A.; Hogland, W.; Marques, M.; Sillanpää, M. An overview of the modification methods of activated carbon for its water treatment applications. Chem. Eng. J. 2013, 219, 499-511. [CrossRef]

32. O'Connor, C.M.; Adams, J.U. Essentials of Cell Biology; NPG Education: Cambridge, MA, USA, 2010.

33. Lipowsky, R.; Sackmann, E. Structure and Dynamics of Membranes: From Cells to Vesicles. In Handbook of Biological Physics; Elsevier: Amsterdam, The Netherlands, 1995; imprint.

34. Lipowsky, R. Self-organization of membranes. Europhys. News 1999, 30, 76-77. [CrossRef]

35. Ringsdorf, H.; Schlarb, B.; Venzmer, J. Molecular Architecture and Function of Polymeric Oriented Systems: Models for the Study of Organization, Surface Recognition, and Dynamics of Biomembranes. Angew. Chem. Int. Ed. 1988, 27, 113-158. [CrossRef]

36. Gau, H. Liquid Morphologies on Structured Surfaces: From Microchannels to Microchips. Science 1999, 283, 46-49. [CrossRef]

37. Lira, R.B.; Steinkühler, J.; Knorr, R.L.; Dimova, R.; Riske, K. Posing for a picture: Vesicle immobilization in agarose gel. Sci. Rep. 2016, 6, 25254. [CrossRef]

38. Fowler, S.; Roush, R.; Wise, J. Concepts of Biology; OpenStax: Houston, TX, USA, 2018.

39. Flood, P.R. Filter characteristics of appendicularian food catching nets. Cell. Mol. Life Sci. 1978, 34, $173-175$. [CrossRef]

40. Flood, P.R.; Deibel, D. The Appendicularian House. In The Biology of Pelagic Tunicates; Bone, Q., Ed.; Oxford University Press: New York, NY, USA, 1998; pp. 105-124.

41. Conley, K.R.; Gemmell, B.J.; Bouquet, J.-M.; Thompson, E.M.; Sutherland, K.R. A self-cleaning biological filter: How appendicularians mechanically control particle adhesion and removal. Limnol. Oceanogr. 2017, 63, 927-938. [CrossRef]

42. Robison, B.H.; Reisenbichler, K.R.; Sherlock, R.E. Giant Larvacean Houses: Rapid Carbon Transport to the Deep Sea Floor. Science 2005, 308, 1609-1611. [CrossRef] [PubMed] 
43. Alldredge, A.L.; Gorsky, G.; Youngbluth, M.; Deibel, D. The contribution of discarded appendicularian houses to the flux of particulate organic carbon from oceanic surface waters. In Response of Marine Ecosystems to Global Change: Ecological Impact of Appendicularians; Éditions Scientifiques: Paris, France, 2005; pp. 309-326.

44. Hansell, M.; Hansell, M.H. Animal Architecture; Oxford University Press: Oxford, UK, 2005.

45. Dawkins, R. The Extended Phenotype; Oxford University Press: Oxford, UK, 1982; Volume 8.

46. Turner, J.S. The Extended Organism: The Physiology of Animal-Built Structures; Harvard University Press: Cambridge, MA, USA, 2009.

47. Geim, A.K.; Novoselov, K.S. The rise of graphene. In Nanoscience and Technology: A Collection of Reviews from Nature Journals; World Scientific: Singapore, 2010; pp. 11-19.

48. Eigler, S.; Hirsch, A. Chemistry with Graphene and Graphene Oxide-Challenges for Synthetic Chemists. Angew. Chem. Int. Ed. 2014, 53, 7720-7738. [CrossRef] [PubMed]

49. Robinson, J.T.; Perkins, F.K.; Snow, E.S.; Wei, Z.; Sheehan, P.E. Reduced Graphene Oxide Molecular Sensors. Nano Lett. 2008, 8, 3137-3140. [CrossRef] [PubMed]

50. Lu, G.; Ocola, L.E.; Chen, J. Reduced graphene oxide for room-temperature gas sensors. Nanotechnology 2009, 20, 445502. [CrossRef]

51. Faghani, A.; Donskyi, I.S.; Gholami, M.F.; Ziem, B.; Lippitz, A.; Unger, W.E.S.; Böttcher, C.; Rabe, J.P.; Haag, R.; Adeli, M. Controlled Covalent Functionalization of Thermally Reduced Graphene Oxide To Generate Defined Bifunctional 2D Nanomaterials. Angew. Chem. 2017, 129, 2719-2723. [CrossRef]

52. Gholami, M.F.; Lauster, D.; Ludwig, K.; Storm, J.; Ziem, B.; Severin, N.; Böttcher, C.; Rabe, J.P.; Herrmann, A.; Adeli, M.; et al. Functionalized Graphene as Extracellular Matrix Mimics: Toward Well-Defined 2D Nanomaterials for Multivalent Virus Interactions. Adv. Funct. Mater. 2017, 27, 1606477. [CrossRef]

53. Ziem, B.; Azab, W.; Gholami, M.F.; Rabe, J.P.; Osterrieder, N.; Haag, R. Size-dependent inhibition of herpesvirus cellular entry by polyvalent nanoarchitectures. Nanoscale 2017, 9, 3774-3783. [CrossRef]

54. Ziem, B.; Thien, H.; Achazi, K.; Yue, C.; Silva, D.V.; Silberreis, K.; Gholami, M.F.; Beckert, F.; Gröger, D.; Mülhaupt, R.; et al. Highly Efficient Multivalent 2D Nanosystems for Inhibition of Orthopoxvirus Particles. Adv. Health Mater. 2016, 5, 2922-2930. [CrossRef]

55. Barth, F.G. A Spider's World: Senses and Behavior; Springer: Berlin/Heidelberg, Germany, 2002.

56. Fratzl, P.; Barth, F.G. Biomaterial systems for mechanosensing and actuation. Nature 2009, 462, 442-448. [CrossRef]

57. McConney, M.E.; Schaber, C.F.; Julian, M.D.; Barth, F.G.; Tsukruk, V.V. Viscoelastic nanoscale properties of cuticle contribute to the high-pass properties of spider vibration receptor (Cupiennius salei Keys). J. R. Soc. Interface 2007, 4, 1135-1143. [CrossRef]

58. Erko, M.; Younes-Metzler, O.; Rack, A.; Zaslansky, P.; Young, S.L.; Milliron, G.; Chyasnavichyus, M.; Barth, F.G.; Fratzl, P.; Tsukruk, V.; et al. Micro- and nano-structural details of a spider's filter for sub- strate vibrations: Relevance for low-frequency signal transmission. J. R. Soc. Interface 2015, 12, 20141111. [CrossRef]

59. Barth, F.G. Spider senses-Technical perfection and biology. Zoology 2002, 105, 271-285. [CrossRef] [PubMed]

60. Young, S.L.; Chyasnavichyus, M.; Erko, M.; Barth, F.G.; Fratzl, P.; Zlotnikov, I.; Politi, Y.; Tsukruk, V.V. A spider's biological vibration filter: Micromechanical characteristics of a biomaterial surface. Acta Biomater. 2014, 10, 4832-4842. [CrossRef] [PubMed]

61. Holter, E.; Muth, S.; Schwesinger, S. Sounding out Public Space in Antiquity: Acoustic Simulations of Public Speeches and Assemblies in Late Republican Rome, in Sound and the Ancient Senses; Butler, S., Nooter, S., Eds.; Routledge: London, UK, 2018; pp. 44-60.

62. Kassung, $\mathrm{C}_{\text {; }}$ Schwesinger, S. How to hear the forum Romanum: On historical realities and aural augmentation. In Kultur und Informatik: Augmented Reality; Busch, C., Sieck, S., Eds.; Werner Hülsbusch: Glückstadt, Germany, 2016; pp. 41-53.

63. Jany, S. Operative Räume. Prozessarchitekturen im späten 19. Jhd. Z. Medienwiss. 2015, 7, $33-43$.

64. Kolarevic, B. Peformative Architecture; Informa UK Limited: London, UK, 2005.

65. Barber, D.A.; Bressani, M.; Darò, C.; Erb, T.; Espahangizi, K.; von Fischer, S.; Harwood, J.; Jachmann, J.; Jany, S.; Martin, R.; et al. Architecture/Machine: Programs, Processes, and Performances; Schwabe AG: Basel, Switzerland, 2018; Volume 1.

66. Lobsinger, M.L. Architectural History: The Turn from Culture to Media. J. Soc. Arch. Hist. 2016, 75, $135-139$. [CrossRef] 
67. Baltzer. Fahrkartenprüfung usw. und Absperrung der Bahnsteige; Zentralblatt d.Bauverwaltungen; Ministerium der öffentlichen Arbeiten: Berlin, Germany, 1983; pp. 249-261.

68. Ebeling, S. Space as Membrane, Trans. In Sypros Papapetros, Introduction by Walter Scheiffle; Pamela, J., Ed.; Architectural Association: London, UK, 1926.

69. Scheiffele, W. Das Leichte Haus: Utopie und Realität der Membranarchitektur; Spectormag GbR: Leipzig, Germany, 2014.

70. Abedjan, Z.; Chu, X.; Deng, D.; Fernandez, R.C.; Ilyas, I.F.; Ouzzani, M.; Papotti, P.; Stonebraker, M.; Tang, N. Detecting Data Errors. Proc. VLDB Endow. 2016, 9, 993-1004. [CrossRef]

71. Abedjan, Z.; Anuth, H.; Esmailoghli, M.; Mahdavi, M.; Neutatz, F.; Chen, B. Data Science für alle: Grundlagen der Datenprogrammierung. Inform. Spektrum 2020, 43, 129-136. [CrossRef]

72. Deng, D.; Fernandez, R.C.; Abedjan, Z.; Wang, S.; Stonebraker, M.; Elmagarmid, A.K.; Ilyas, I.F.; Madden, S.; Ouzzani, M.; Tang, N. The Data Civilizer System. In Proceedings of the 8th Biennial Conference on Innovative Data Systems Research (CIDR ‘17), Chaminade, CA, USA, 8-11 January 2017.

73. Shang, Z.; Zgraggen, E.; Buratti, B.; Kossmann, F.; Eichmann, P.; Chung, Y.; Binnig, C.; Upfal, E.; Kraska, T. Democratizing data science through interactive curation of $\mathrm{ml}$ pipelines. In Proceedings of the 2019 International Conference on Management of Data, Amsterdam, The Netherlands, 30 June-5 July 2019; pp. 1171-1188.

74. Hui, Y.; Stiegler, B. On the Existence of Digital Objects; University of Minnesota Press: Minneapolis, MN, USA, 2016.

75. Lanier, J. Ten Arguments for Deleting Your Social Media Accounts Right Now; Random House: New York, NY, USA, 2018.

76. Zuboff, S. The Age of Surveillance caPitalism: The Fight for a Human Future at the New Frontier of Power; Profile Books: London, UK, 2019.

77. Baudrillard, J. Simulacra and Simulation; University of Michigan Press: Ann Arbor, MI, USA, 1994.

78. Derrida, J. Archive Fever: A Freudian Impression; Prenowitz, E., Translator; University of Chicago Press: Chicago, IL, USA, 1996.

79. Chen, A. The laborers who keep dick pics and beheadings out of your Facebook feed. Wired 2014, $23,14$.

80. Block, H.; Riesewieck, M. The Cleaners (Im Schatten der Netzwelt); Farbfilm verleih GmbH: Berlin, Germany, 2018.

81. Derycke, L. Screener-Die dunklen Seiten des Internets; WDR 3 Hörspiel, Deutschlandfunk Kultur: Berlin, Germany, 2016.

82. Yaghmaei, E.; Porcari, A.; Mantovani, E.; Flipse, S.M. Monitoring the Value of Responsible Research and Innovation in Industrial Nanotechnology Innovation Projects. In Nanotechnology: Regulation and Public Discourse; Eisenberger, I., Kallhoff, A., Schwarz-Plaschg, C., Eds.; Rowman \& Littlefield: Lanham, MD, USA, 2019.

83. Yaghmaei, E.; Van de Poel, I. Assessment of Responsible Innovation: Methods and Practices; Routledge: Abingdon-on-Thames, UK, 2020. ISBN 9780367279752.

84. Von Schomberg, R. Towards Responsible Research and Innovation in the Information and Communication Technologies and Security Technologies Fields. SSRN Electron. J. 2011. [CrossRef]

85. Stilgoe, J.; Owen, R.; Macnaghten, P. Developing a framework for responsible innovation. Res. Policy 2013, 42, 1568-1580. [CrossRef]

86. Yaghmaei, E. Responsible research and innovation key performance indicators in industry: A case study in the ICT domain. J. Inf. Commun. Ethics Soc. 2018, 16, 214-234.

87. Morrison-Saunders, A.; Sánchez, L.E.; Retief, F.; Sinclair, J.; Doelle, M.; Jones, M.; Wessels, J.-A.; Pope, J. Gearing up impact assessment as a vehicle for achieving the UN sustainable development goals. Impact Assess. Proj. Apprais. 2019, 38, 113-117. [CrossRef]

88. Schüttpelz, E. Die medienanthropologische Kehre der Kulturtechniken. Arch. Medien. 2006, 6, 87-110.

89. Macho, T. Zeit und Zahl. In Kalender und Zeitrechnung als Kulturtechniken; Zahl, B.S., Krämer, S., Bredekamp, H., Eds.; Wilhelm Fink: München, Germany, 2003; pp. 179-192.

90. Siegert, B. Cacography or Communication? Cultural Techniques in German Media Studies. Grey Room 2007, 29, 26-47. [CrossRef]

91. Butler, J. Bodies that Matter: On the Discursive Limits of Sex; Taylor \& Francis Group (Routledge): New York, NY, USA; London, UK, 2011. 
92. Loxley, J. Performativity; Routledge: London, UK, 2006.

93. Austin, J. How to Do Things with Words; Oxford University Press (OUP): Oxford, UK, 1975; Volume 88.

94. Barad, K. Meeting the Universe Halfway, Quantum Physics and the Entanglement of Matter and Meaning; Duke University Press: Durham, UK, 2007.

95. Gaskell, D.R.; Laughlin, D.E. Introduction to the Thermodynamics of Materials; CRC Press: Boca Raton, FL, USA, 2017; Chapter 4.

96. Brillouin, L. The Negentropy Principle of Information. J. Appl. Phys. 1953, 24, 1152. [CrossRef]

97. Schrödinger, E. What is Life - The Physical Aspect of the Living Cell; Cambridge University Press: Cambridge, UK, 1944.

98. Mahulikar, S.P.; Herwig, H. Exact thermodynamic principles for dynamic order existence and evolution in chaos. Chaos Solitons Fractals 2009, 41, 1939-1948. [CrossRef]

99. Shannon, C.E. A mathematical theory of communication. Bell Syst. Tech. J. 1948, 27, 379-423. [CrossRef]

100. Deacon, T.W. Shannon-Boltzmann-Darwin: Redefining information (Part I). In Cognitive Semiotics; De Gruyter Mouton: Berlin, Germany, 2007; pp. 123-148.

101. Deacon, T.W. Shannon-Boltzmann-Darwin: Redefining information (Part II). In Cognitive Semiotics; De Gruyter Mouton: Berlin, Germany, 2008; pp. 169-196.

102. Deacon, T.W. Incomplete Nature: How Mind Emerged from Matter; W.W. Norton \& Company: New York, NY, USA, 2011.

103. Rocha, L.M. Selected Self-Organization and the Semiotics of Evolutionary Systems. In Evolutionary Systems; Springer: Dordrecht, The Netherlands, 1998; pp. 341-358.

104. Dennett, D.C. From Bacteria to Bach and Back: The Evolution of Minds; W.W Norton \& Company: New York, NY, USA, 2017.

105. Caillois, R.; Fradier, M. Dynamics of Dissymmetry. Diogenes 1971, 19, 62-92. [CrossRef]

106. Prigogine, I.; Stengers, I. Order out of Chaos: Man's New Dialogue with Nature; Verso Books: London, UK, 2018.

107. Dennett, D.C. The Intentional Stance; MIT Press: Cambridge, MA, USA, 1989.

108. Raabe, D.; Tasan, C.C.; Olivetti, E. Strategies for improving the sustainability of structural metals. Nature 2019, 575, 64-74. [CrossRef]

109. MacArthur, E. Towards the Circular Economy, Economic and Business rAtionale for an Accelerated Transition; Ellen MacArthur Foundation: Cowes, UK, 2013; pp. 21-34.

110. Schill, C.; Anderies, J.M.; Lindahl, T.; Folke, C.; Polasky, S.; Cãjrdenas, J.C.; Crépin, A.-S.; Janssen, M.A.; Norberg, J.; Schlüter, M. A more dynamic understanding of human behaviour for the Anthropocene. Nat. Sustain. 2019, 2, 1075-1082. [CrossRef] 